\title{
Efficacy and safety of pharmacotherapy for Alzheimer's disease and for behavioural and psychological symptoms of dementia in older patients with moderate and severe functional impairments: a systematic review of controlled trials
}

\author{
M. Seibert', V. Mühlbauer, 2,3, J. Holbrook' , S. Voigt-Radloff ${ }^{4,5}$, S. Brefka ${ }^{2,3}$, D. Dallmeier ${ }^{2,3,6}$, M. Denkinger ${ }^{2,3}$, \\ C. Schönfeldt-Lecuona ${ }^{3,7}$, S. Klöppel ${ }^{8}$ and C. A. F. von Arnim ${ }^{3,9^{*}}$
}

\begin{abstract}
Background: Many patients with Alzheimer's disease (AD) are physically frail or have substantial functional impairments. There is growing evidence that such patients are at higher risk for medication-induced adverse events. Furthermore, frailty seems to be more predictive of poor clinical outcomes than chronological age alone. To our knowledge, no systematic review of clinical trials examining drug therapy of AD or behavioural and psychological symptoms of dementia (BPSD) has specifically focused on the topic of physical frailty. Our objective was to evaluate the efficacy and safety of pharmacotherapy in AD patients with frailty or significant functional impairments.

Methods: We performed a systematic literature search in MEDLINE, Embase and the Cochrane Central Register of Controlled Trials (CENTRAL) for randomized controlled trials (RCTs) of drug therapy of AD and BPSD in patients with significant functional impairments according to the Preferred Reporting Items for Systematic Reviews and MetaAnalyses (PRISMA) statement and Cochrane research criteria. Significant functionally impaired patient populations were identified using the recommendations of the Medication and Quality of Life in frail older persons (MedQoL) Research Group. Screening, selection of studies, data extraction and risk of bias assessment were performed independently by two reviewers. Outcomes including functional status, cognitive function, changes in BPSD symptoms, clinical global impression and quality of life were analysed. For assessing harm, we assessed adverse events, drop-outs as a proxy for treatment tolerability and death. Results were analysed according to Cochrane standards and the Grading of Recommendations Assessment, Development and Evaluation (GRADE) approach.
\end{abstract}

\footnotetext{
* Correspondence: christine.arnim@med.uni-goettingen.de

${ }^{3}$ Geriatric Center Ulm/Alb-Donau, Ulm, Germany

${ }^{9}$ Division of Geriatrics, University Medical Centre, Georg August University, Robert-Koch-Str. 40, 37075 Göttingen, Germany

Full list of author information is available at the end of the article
}

(c) The Author(s). 2021 Open Access This article is licensed under a Creative Commons Attribution 4.0 International License, which permits use, sharing, adaptation, distribution and reproduction in any medium or format, as long as you give appropriate credit to the original author(s) and the source, provide a link to the Creative Commons licence, and indicate if changes were made. The images or other third party material in this article are included in the article's Creative Commons licence, unless indicated otherwise in a credit line to the material. If material is not included in the article's Creative Commons licence and your intended use is not permitted by statutory regulation or exceeds the permitted use, you will need to obtain permission directly from the copyright holder. To view a copy of this licence, visit http://creativecommons.org/licenses/by/4.0/. The Creative Commons Public Domain Dedication waiver (http://creativecommons.org/publicdomain/zero/1.0/) applies to the data made available in this article, unless otherwise stated in a credit line to the data. 
Results: Of 45,045 search results, 38,447 abstracts and 187 full texts were screened, and finally, 10 RCTs were included in the systematic review. Selected articles evaluated pharmacotherapy with acetylcholinesterase-inhibitors (AChEI), anticonvulsants, antidepressants and antipsychotics. Studies of AChEls suggested that patients with significant functional impairments had slight but significant improvements in cognition and that AChEls were generally well tolerated. Studies of antidepressants did not show significant improvements in depressive symptoms. Antipsychotics and anticonvulsants showed small effects on some BPSD items but also higher rates of adverse events. However, due to the very small number of identified trials, the quality of evidence for all outcomes was low to very low.

Overall, the small number of eligible studies demonstrates that significantly functional impaired older patients have not been adequately taken into consideration in most clinical trials investigating drug therapy of AD and BPSD.

Conclusion: Due to lack of evidence, it is not possible to give specific recommendations for drug therapy of AD and BSPD in frail older patients or older patients with significant functional impairments. Therefore, clinical trials focussing on frail older adults are urgently required. A standardized approach to physical frailty in future clinical studies is highly desirable.

Keywords: Frail elderly, Alzheimer's disease, Dementia, BPSD, Systematic review, Drug therapy

\section{Introduction}

People over the age of 75 years are the world's fastestgrowing demographic group. Health systems worldwide must meet new challenges generated by the ageing population, including the medical care of frail older patients $[1,2]$. With increasing population age, the prevalence of age-associated conditions such as Alzheimer's disease (AD) and frailty will also rise [3, 4]. Factors such as frailty or disability appear to be more predictive for detrimental outcomes (e.g., mortality) than chronological age alone [5-7]. Although the International Council for Harmonisation of Technical Requirements for Pharmaceuticals for Human Use (ICH) recommended the inclusion of frail older patients in RCTs as far back as 1993, these patients are still seldom included in RCTs [8-11]. Therefore, although such patients are overrepresented in real-world clinical settings, as they often have multiple morbidities and are recipients of polypharmacy, they are underrepresented in the studies that provide the data on which clinical treatments are based [12]. Due to the lack of available evidence, frailty is also often ignored during the formulation of medical guidelines [13]. It is wellknown that medications may have different effects in this vulnerable population: impaired functional status, systemic illness and metabolic changes may result in different pharmacologic and pharmacodynamic responses, a different adverse event profile and ultimately a different risk-benefit calculus [12, 14, 15].

Despite its importance as a medical concept, there is still no clear universally accepted definition of frailty. Frailty is generally described as an age-associated syndrome with increased vulnerability to minor stressor events because of impairments in multiple systems [16, 17]. The concept of frailty takes biological age into account rather than chronological age. Many different approaches are used to estimate frailty $[18,19]$. The two most used are the (i) Frailty Phenotype by Fried et al. and the (ii) Frailty Index (FI) by Rockwood and Mitnitski. The so-called Frailty Phenotype mainly applies to physical frailty, as assessed by reduced grip strength, unintended weight loss, exhaustion, decreased physical activity and slow gait speed [16]. Rockwood and Mitnitski have proposed defining frailty by an accumulation of deficits, including but not limited to functional items, and mainly relying on comorbidities, including cognitive impairments [20]. Frailty is however in both concepts tightly linked to functional status. Patients with AD have more comorbidities and are more often physically frail than patients without AD [21-23]. Conversely, some evidence indicates that frail older patients may have a higher risk of developing $\mathrm{AD}$; furthermore, higher frailty scores are associated with a more rapid cognitive decline $[24,25]$. Frailty may also result in a higher risk of adverse events from drug therapy for $\mathrm{AD}$, for instance, during the use of antidementia medications such as acetylcholinesterase inhibitors [14, 26].

Frailty of $\mathrm{AD}$ patients also correlates with the severity of behavioural and psychological symptoms of dementia (BPSD, e.g. psychosis, depression, apathy, agitation, aggression and sleep disturbances) and caregiver burden $[27,28]$. Reciprocally, AD patients with BPSD are more likely to be frail and may also have a higher risk for adverse events such as falls during drug therapy [29]. Drug therapy of BPSD in patients with $\mathrm{AD}$ is usually recommended only when psychosocial interventions or other nonpharmacological interventions are not sufficient [30]. BPSD is a substantial consideration in patients with $\mathrm{AD}$ and has a major impact on patients' and caregivers' quality of life [31,32]. Common therapies for 
BPSD often consist of psychopharmacotherapy (e.g. antipsychotics, antidepressants or even anticonvulsants), many of which may have anticholinergic properties and are possibly inappropriate for geriatric patients, as indicated in the Beers' criteria list or the PRISCUS list [33, 34].

Despite the broad importance of drug therapy for the treatment of cognitive and BPSD symptoms in frail AD patients, to our knowledge, there has been no systematic review in this population, even though the available literature suggests a different risk-benefit ratio due to a higher rate of adverse events. Current evidence mainly relies on a mere handful of RCTs. The objective of this review was to determine the efficacy and safety of drug therapy for frail older patients with Alzheimer's disease and associated BPSD. Is there sufficient evidence to recommend safe and effective treatments for this vulnerable patient population?

\section{Methods}

The review process was performed according to the Preferred Reporting Items for Systematic Reviews and Meta-Analyses (PRISMA) statement and the Cochrane Handbook for Systematic Reviews of Interventions [35, 36].

\section{Types of studies}

We included double-blind RCTs comparing pharmacotherapy of $\mathrm{AD}$ or $\mathrm{BPSD}$ in $\mathrm{AD}$ with placebo or other drug interventions and involving frail older patients. Studies in any settings were included (outpatient, inpatient, long term care facilities or nursing homes). Studies including patients with dementia or with neuropsychiatric symptoms not in the context of $\mathrm{AD}$ were excluded.

\section{Types of participants}

The patients in included trials had to be diagnosed with $\mathrm{AD}$ according to internationally accepted criteria such as the Diagnostic and Statistical Manual of Mental Disorders criteria IV and 5 (DSM IV/DSM-5) [37, 38], International Classification of Diseases 10 (ICD10) [39] or the National Institute of Neurological and Communicative Disorders and Stroke-Alzheimer's Disease and Related Disorders Association (NINCDSADRDA) criteria [40]. Studies were also eligible if AD patients constituted a major part of the study population (>50\%), even if other types of dementia were also included. Patient populations with BPSD resulting from $\mathrm{AD}$ were also considered. A mean age of 70 years or more or a minimum age of 65 years was required.

\section{Physical frailty/functional impairment evaluation}

To evaluate physical frailty and/or significant functional impairments, the patient population in RCTs was classified according to the Medication and Quality of Life in Frail Older Persons (MedQoL) Research Group criteria, which define cut-offs for 51 established scores and differentiates between functionally independent, functionally slightly impaired, functionally significantly impaired/ partially dependent and functionally severely impaired/ disabled/mostly or totally dependent [41]. The study population had to be rated on average as at least "significantly impaired or partially dependent" to allow inclusion in this review. However, studies in which frailty was defined mainly based on cognitive impairment were excluded, because this could have resulted in AD patients being included only on the basis of their associated cognitive deficits. This was discussed within the MedQoL Research Group and mutually agreed upon. Using this methodology, we identified study patient populations that were likely to be physically frail or significantly functionally impaired (but not primarily due to cognitive deficits).

\section{Types of interventions}

Any pharmacotherapies for AD and BPSD in any dosage or treatment duration were included.

Types of outcome measures

The following outcomes were defined [42]:

- Functional status as rated by MedQoL criteria [41],

- Cognitive function (as measured by psychometric tests),

- Changes in BPSD symptoms (as measured by psychometric tests or questionnaires),

- Clinical global impression, and

- Quality of life.

For assessing harm, we determined the outcomes:

- Adverse events,

- Drop-outs as a proxy for treatment tolerability, and

- Death.

These outcomes correspond to the AD-recommended outcomes for $\mathrm{AD}$ trials by the IQWiG (Institute for Quality and Efficiency in Health Care) and the EMA (European Medicines Agency) [43, 44].

\section{Search methods for identification of studies}

We searched the following databases: Embase, MEDL INE and the Cochrane Central Register of Controlled Trials (CENTRAL), on 24/06/2017. There was no restriction on publication language. An update search was 
performed on 15/01/2019. We defined 1 January 1992 as the publication period's lower limit, as it was about the time of the introduction of the term "frailty" in current literature [45].

In addition, the German national guidelines for therapy of AD and BPSD and the references from systematic reviews were also screened for relevant studies. All identified publications were imported in Covidence ${ }^{1}[46]$ and then independently screened by two reviewers (VM, MS). If the authors disagreed on a study's inclusion, discussion was continued until consensus was reached; otherwise, a third review author (CvA) was consulted.

\section{Data extraction and risk of bias assessment}

Data were independently extracted by two review authors (VM, MS) using a standardized data collection form by the Cochrane Effective Practice and Organisation of Care (EPOC) group [47]. Whenever data were not reported or were not suitable for extraction the corresponding author was contacted. Missing standard deviations (SD) were calculated using other reported statistical data.

The risk of bias assessment was performed independently by two review authors (VM, MS) using the Cochrane Collaboration's tool for assessing risk of bias in RCTs [48].

For each publication, the risk of bias was rated as high, low or unclear. If authors disagreed, discussion was continued until consensus was reached; otherwise, a third review author (CvA) was consulted.

\section{Data analysis}

We calculated mean differences (MD) or standardized mean differences (SMD) for continuous outcomes or the risk ratio (RR) for dichotomous outcomes, and the corresponding 95\% confidence interval (CIs) using a fixedeffect model. A probability value of $<0.05$ was determined to be the significance level.

Heterogeneity was assessed using the $\mathrm{I}^{2}$ test. For probably relevant heterogeneity $\left(\mathrm{I}^{2}\right.$ value $\geq 50 \%$ ), possible causes were examined, and a random-effect model was used.

We analysed shorter ordinal scores such as the Clinical Global Impression - Improvement Scale (CGI-I, a 7point Likert scale) as dichotomous outcomes by combining adjacent categories into two groups: "worsening/no change" or "clinical improvement".

When analysing outcomes of cross-over trials, potentially relevant carry-over effects or other issues regarding the cross-over study design were handled by only including study data of the first treatment period.

${ }^{1}$ Covidence is the primary screening and data extraction tool for Cochrane authors.
The statistical analysis was performed using Review Manager 5.3 (RevMan) by the Cochrane Collaboration (MS) [49].

\section{Quality of evidence ratings}

Quality of evidence was assessed using the Grading of Recommendations Assessment, Development and Evaluation (GRADE) approach [50, 51]. GRADE ratings were performed by two review authors independently (VM, MS) according to recommendations of the GRADE handbook [52].

Using the GRADE approach, quality of evidence (very low/low/moderate/high) for most important outcomes are rated separately using the following explicit criteria: study design, risk of bias, imprecision, inconsistency, indirectness and magnitude of effect. The following outcome groups were considered as most important and included in GRADE ratings: functional status, cognitive function, BPSD, adverse events, treatment tolerability, death and quality of life.

Imprecision ratings for continuous outcomes were performed considering the minimally important difference (MID) (see Additional file 1).

If there was no published MID, Hedges' $\mathrm{g}$ was calculated to determine potentially relevant treatment effects. An effect size (Hedges' g) of $\geq 0.2$ was considered as an MID, whereas Hedges' $g<0.2$ was considered as no relevant treatment effect. For further classification of the magnitude of the effect size we used the recommendations by Cohen: $0.2=$ small, $0.5=$ medium, $0.8=$ large [53]. A study population of fewer than 400 was considered as too small to ensure adequate precision of outcomes [54].

When rating imprecision of outcomes for dichotomous data, the figure by Guyatt et al. with a $25 \%$ relative risk reduction (RRR) was used to estimate the acceptable size for a study population. In addition, a 95\% CI including a RR of at least 0.75 to 1.25 was considered as large [54]. GRADE ratings and the creation of summary of findings tables were performed using GRADEpro [55].

\section{Results}

The online searches performed in 2017 and 2019 retrieved 45,045 records. In addition, the search for potentially relevant publications used in systematic reviews and of the German national guidelines for dementia retrieved 99 records. After removing duplicates, 38,447 titles and abstracts were screened, and 187 full texts were read. Reasons for exclusion are shown in Fig. 1. Finally, 10 studies were included in this systematic review.

\section{Characteristics of included studies}

All study populations were at least 70 years on average and mostly "significantly impaired" according to 


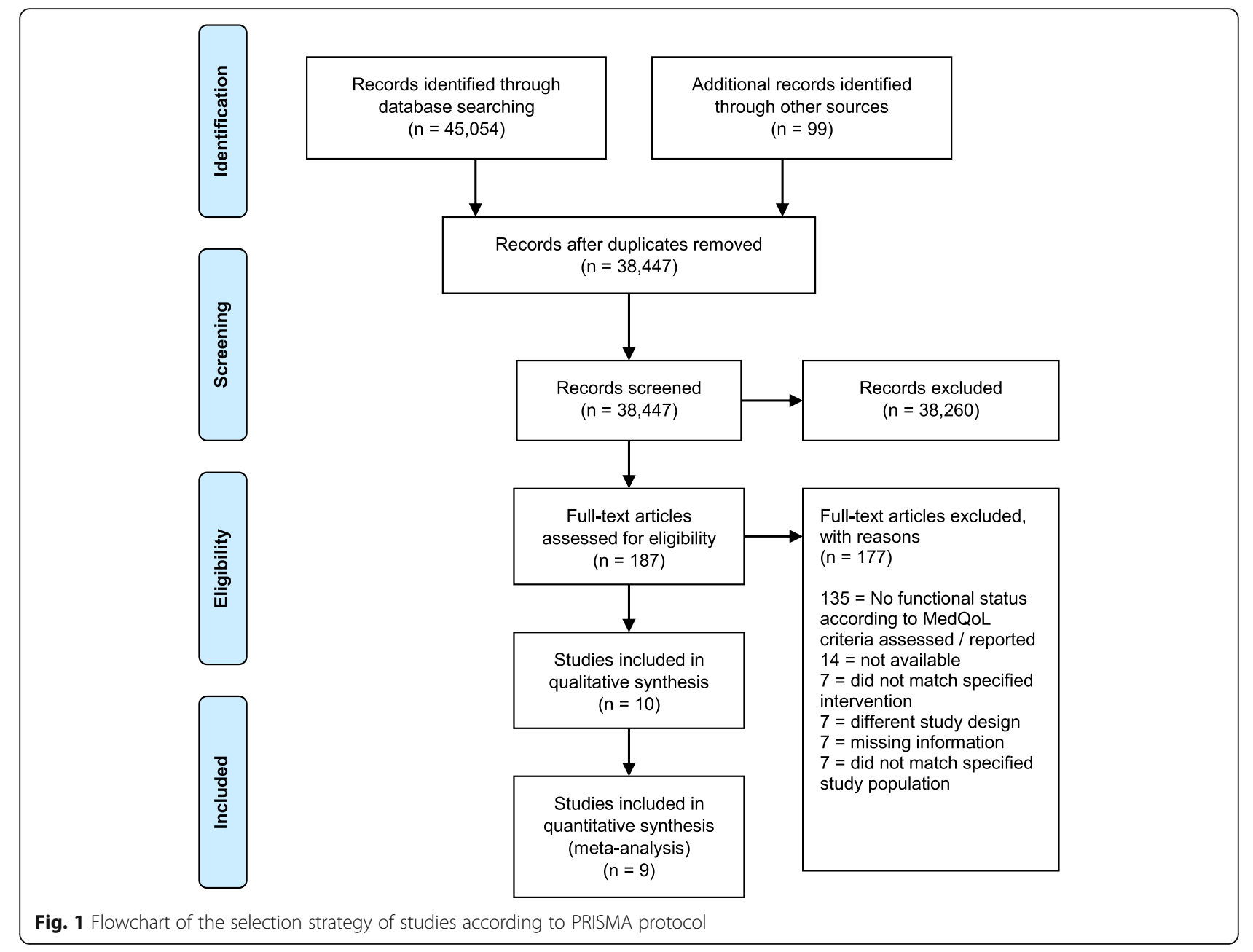

MedQoL criteria. Included studies used the PSMS, the FIM or the MDS-ADL scales, which we used to assess impairment in physical function for frailty evaluation according to MedQoL criteria (see Additional file 2). Ten RCTs were included in the systematic review: two studies evaluated AChEIs, four studies anticonvulsants, two studies antidepressants, one study antipsychotics and one triple-arm study investigated one antidepressant and one antipsychotic medication. Female patients constituted the majority of participants (61-100\%) in every treatment group in the included studies, except for the fluoxetine group of Petracca et al. (2001) (47\% female) [56]. All studies used the oral drug administration route only. Tolerability and safety were assessed by the number and types of adverse events and the drop-out rate during the treatment period. Quality of life was not assessed in any of the studies. For more detailed study information, see Table 1.

\section{Acetylcholinesterase inhibitors}

Burns et al. compared galantamine with placebo in patients in residential homes, nursing homes or geriatric residences with severe $\mathrm{AD}$ in 57 European investigational sites using a multicentre design [57], and Tariot et al. focussed on patients in nursing homes with moderate $\mathrm{AD}$ in 27 US nursing homes and compared donepezil with placebo [58]. Both trials' treatment duration was about 6 months.

\section{Antidepressants}

Two studies were included investigating the efficacy and safety of antidepressants (fluoxetine or clomipramine) in outpatients with depression and mild AD in Argentina for 6 weeks $[56,59]$. Unfortunately, the cross-over trial by Petracca et al. (1996) reported no suitable data for extraction and no additional study data could be acquired [59]. Therefore, the study data were only analysed qualitatively, except for adverse events of the first treatment period.

\section{Antidepressants/antipsychotics}

We identified a 3-arm study comparing the efficacy and safety of flexibly-dosed fluvoxamine, risperidone and the traditional Japanese herbal medicine yokukansan for 8 
Table 1 Characteristics of included studies

\begin{tabular}{|c|c|c|c|c|c|c|c|c|}
\hline & $\begin{array}{l}\text { Study } \\
\text { (Author, } \\
\text { year) }\end{array}$ & Duration & $\begin{array}{l}\text { Sample } \\
\text { size }(n)\end{array}$ & $\begin{array}{l}\text { Age of study } \\
\text { population } \\
\text { (IG/CG) }\end{array}$ & $\begin{array}{l}\text { Baseline } \\
\text { MMSE } \\
\text { (IG/CG) }\end{array}$ & Intervention & Endpoints & Results \\
\hline \multirow[t]{2}{*}{ AChEl } & $\begin{array}{l}\text { Burns et al., } \\
2009 \text { [57] }\end{array}$ & 6 months & 407 & $83.7 / 83.5$ & $8.8 / 9.1$ & $\begin{array}{l}\text { Galantamine: } \\
24 \mathrm{mg} / \text { day target dose } \\
\text { (12 mg twice a day). } \\
\text { Dose reduction to } 8 \mathrm{mg} \\
\text { twice a day to improve } \\
\text { tolerability was possible. } \\
\text { Placebo. }\end{array}$ & $\begin{array}{l}\text { MDS-ADL, } \\
\text { SIB }\end{array}$ & $\begin{array}{l}\text { Significantly improved } \\
\text { cognitive function. No } \\
\text { significant improvement } \\
\text { in the co-primary out- } \\
\text { come of ADLs. }\end{array}$ \\
\hline & $\begin{array}{l}\text { Tariot et al., } \\
2001 \text { [58] }\end{array}$ & 24 weeks & 208 & $85.4 / 85.9$ & 14.4 & $\begin{array}{l}\text { Donepezil: } \\
10 \text { mg/day target dose. } \\
\text { Dose reduction to } \\
\text { improve tolerability was } \\
\text { possible. } \\
\text { Placebo. }\end{array}$ & $\begin{array}{l}\text { CDR-SOB, } \\
\text { MMSE, } \\
\text { NPI-NH, } \\
\text { PSMS }\end{array}$ & $\begin{array}{l}\text { Donepezil-treated } \\
\text { patients improved or } \\
\text { maintained in cognition. } \\
\text { Impact of donepezil on } \\
\text { BPSD remains unclear. }\end{array}$ \\
\hline \multirow[t]{2}{*}{ Antidepressants } & $\begin{array}{l}\text { Petracca } \\
\text { et al., } 1996 \\
\text { [59] } \\
\text { (cross-over } \\
\text { trial) }\end{array}$ & $\begin{array}{l}2 \times 6 \text { week } \\
\text { treatment } \\
\text { period, } \\
\text { separated } \\
\text { by a 2-week } \\
\text { wash-out } \\
\text { period }\end{array}$ & 24 & $71.5 / 72.4$ & 21.0/22.1 & $\begin{array}{l}\text { Clomipramine: } 100 \text { mg/ } \\
\text { day target dose. } \\
\text { Placebo. }\end{array}$ & $\begin{array}{l}\text { FIM, HAM- } \\
\text { D, MMSE }\end{array}$ & $\begin{array}{l}\text { Clomipramine was } \\
\text { significantly more } \\
\text { effective in lowering } \\
\text { depression scores } \\
\text { compared to placebo. No } \\
\text { changes in ADL } \\
\text { measures. }\end{array}$ \\
\hline & $\begin{array}{l}\text { Petracca } \\
\text { et al., } 2001 \\
{[56]}\end{array}$ & 6 weeks & 41 & $70.2 / 71.3$ & 23.2 & $\begin{array}{l}\text { Fluoxetine: } \\
40 \text { mg/day target dose. } \\
\text { Placebo. }\end{array}$ & $\begin{array}{l}\text { CGI-I, FIM, } \\
\text { HAM-A, } \\
\text { HAM-D, } \\
\text { MMSE }\end{array}$ & $\begin{array}{l}\text { No significant differences } \\
\text { in treatment effects on } \\
\text { depression comparing } \\
\text { fluoxetine and placebo. }\end{array}$ \\
\hline \multirow[t]{4}{*}{ Anticonvulsants } & $\begin{array}{l}\text { Olin et al., } \\
2001 \text { [60] }\end{array}$ & 6 weeks & 21 & 74.7 & $5.9 / 6.1$ & $\begin{array}{l}\text { Carbamazepine: } 400 \text { mg/ } \\
\text { day target dose. } \\
\text { Placebo. }\end{array}$ & $\begin{array}{l}\text { BPRS, CGI- } \\
\text { I, HAM-D, } \\
\text { IADL, } \\
\text { MMSE, } \\
\text { PSMS }\end{array}$ & $\begin{array}{l}\text { Modest clinical benefit in } \\
\text { global impression and a } \\
\text { particular benefit for } \\
\text { hostile behaviour in } \\
\text { carbamazepine-treated } \\
\text { patients was shown. }\end{array}$ \\
\hline & $\begin{array}{l}\text { Porsteinsson } \\
\text { et al., } 2001 \\
{[61]}\end{array}$ & 6 weeks & 56 & $85.3 / 84.7$ & $7.0 / 6.7$ & $\begin{array}{l}\text { Carbamazepine: } 375 \text { mg/ } \\
\text { day starting dose, } \\
\text { followed by flexible } \\
\text { dose regimen. } \\
\text { Placebo. }\end{array}$ & $\begin{array}{l}\text { BPRS, } \\
\text { CERAD } \\
\text { BRSD, CGI- } \\
\text { I, MMSE, } \\
\text { OAS, PSMS }\end{array}$ & $\begin{array}{l}\text { Possible short-term effi- } \\
\text { cacy of valproate in re- } \\
\text { duction of agitation in } \\
\text { patients with dementia in } \\
\text { the nursing home. }\end{array}$ \\
\hline & $\begin{array}{l}\text { Tariot et al., } \\
1994[62] \\
\text { (cross-over } \\
\text { trial) }\end{array}$ & $\begin{array}{l}2 \times 5 \text { week } \\
\text { treatment } \\
\text { period, } \\
\text { separated } \\
\text { by a } 2 \text { week } \\
\text { wash-out } \\
\text { period }\end{array}$ & 25 & 84.5 & 7.6 & $\begin{array}{l}\text { Carbamazepine: } 100- \\
800 \text { mg/day based on } \\
\text { physician's review. }\end{array}$ & $\begin{array}{l}\text { BPRS, CGI- } \\
\text { l, DMAS, } \\
\text { MMSE, } \\
\text { OAS, PSMS }\end{array}$ & $\begin{array}{l}\text { Short-term therapy with } \\
\text { Carbamazepine may have } \\
\text { beneficial effects on BPSD } \\
\text { in patients with dementia } \\
\text { and agitation (significant } \\
\text { reduction in BPRS total } \\
\text { score). }\end{array}$ \\
\hline & $\begin{array}{l}\text { Tariot et al., } \\
1998 \text { [63] }\end{array}$ & 6 weeks & 51 & $87.1 / 84.8$ & $3.9 / 8.3$ & $\begin{array}{l}\text { Carbamazepine: } 100 \mathrm{mg} / \\
\text { day starting dose, } \\
\text { increased by } 50 \mathrm{mg} / \text { day } \\
\text { every } 2-4 \text { days; in the } \\
\text { absence of toxicity a } \\
\text { serum level of } 5-8 \mathrm{\mu g} / \\
\text { ml was maintained. } \\
\text { Placebo. }\end{array}$ & $\begin{array}{l}\text { BPRS, } \\
\text { CERAD } \\
\text { BRSD, CGI- } \\
\text { I, MMSE, } \\
\text { PSMS }\end{array}$ & $\begin{array}{l}\text { Carbamazepine showed } \\
\text { significant short-term effi- } \\
\text { cacy for agitation. Signifi- } \\
\text { cant reduction of the } \\
\text { BPRS agitation and hostil- } \\
\text { ity factor compared with } \\
\text { placebo. }\end{array}$ \\
\hline Antipsychotics & $\begin{array}{l}\text { Tariot et al., } \\
2006 \text { [64] }\end{array}$ & 10 weeks & 284 & $\begin{array}{l}\text { Q: } 81.9 \\
\text { H: } 83.6 \\
\text { P: } 83.9\end{array}$ & $\begin{array}{l}\text { Q: } 12.4 \\
\text { H: } 12.7 \\
\text { P: } 13.2\end{array}$ & $\begin{array}{l}\text { Quetiapine: } \\
100 \text { mg/day target dose, } \\
\text { maximum dose of } 600 \\
\text { mg/day according to } \\
\text { clinical response and } \\
\text { tolerability } \\
\text { Haloperidol: } \\
2 \text { mg/day target dose, } \\
\text { maximum dose of } 12 \\
\text { mg/day according to } \\
\text { clinical response and }\end{array}$ & $\begin{array}{l}\text { AIMS, } \\
\text { BPRS, CGI- } \\
\text { S, MMSE, } \\
\text { MOSES, } \\
\text { NPI-NH, } \\
\text { PSMS, SAS } \\
\end{array}$ & $\begin{array}{l}\text { No significant } \\
\text { improvement in BPRS } \\
\text { total scores. Inconsistent } \\
\text { significant improvement } \\
\text { in some parts of BPSD for } \\
\text { haloperidol treated } \\
\text { patients. Tolerability was } \\
\text { better for quetiapine } \\
\text { compared with } \\
\text { haloperidol. }\end{array}$ \\
\hline
\end{tabular}


Table 1 Characteristics of included studies (Continued)

\begin{tabular}{|c|c|c|c|c|c|c|c|c|}
\hline & $\begin{array}{l}\text { Study } \\
\text { (Author, } \\
\text { year) }\end{array}$ & Duration & $\begin{array}{l}\text { Sample } \\
\text { size }(n)\end{array}$ & $\begin{array}{l}\text { Age of study } \\
\text { population } \\
\text { (IG/CG) }\end{array}$ & $\begin{array}{l}\text { Baseline } \\
\text { MMSE } \\
\text { (IG/CG) }\end{array}$ & Intervention & Endpoints & Results \\
\hline & & & & & & Placebo. & & \\
\hline $\begin{array}{l}\text { Antipsychotics/ } \\
\text { antidepressants }\end{array}$ & $\begin{array}{l}\text { Teranishi } \\
\text { et al., } 2013 \\
\text { [65] }\end{array}$ & 8 weeks & 82 & $\begin{array}{l}\text { R: } 80.7 \\
\text { F: } 83.2 \\
\text { Y: } 83.5\end{array}$ & $\begin{array}{l}\text { R: } 5.2 \\
\text { F: } 4.5 \\
\text { Y: } 4.4\end{array}$ & $\begin{array}{l}\text { Flexible oral dosing } \\
\text { regimen. } \\
\text { Risperidone: } \\
0.5-2 \mathrm{mg} / \text { day target } \\
\text { dose. } \\
\text { Fluvoxamine: } \\
25-200 \mathrm{mg} / \text { day target } \\
\text { dose. } \\
\text { Yokukansan: } 2.5-7.5 \mathrm{~g} / \\
\text { day target dose. }\end{array}$ & $\begin{array}{l}\text { DIEPSS, } \\
\text { FIM, } \\
\text { MMSE, } \\
\text { NPI-NH }\end{array}$ & $\begin{array}{l}\text { NPI-NH scores decreased } \\
\text { in all three groups with } \\
\text { no significant differences. } \\
\text { Tolerability for } \\
\text { yokukansan and } \\
\text { quetiapine seemed to be } \\
\text { more favourable than for } \\
\text { risperidone. }\end{array}$ \\
\hline
\end{tabular}

CG control group, $F$ fluvoxamine, $H$ haloperidol, IG intervention group, $P$ placebo, $Q$ quetiapine, $R$ risperidone, $Y$ yokukansan; Endpoints: $A I M S$ Abnormal Involuntary Movement Scale, BPRS Brief Psychiatric Rating Scale, CDR-SoB Clinical Dementia Rating - Sum of Boxes, CERAD BRSD Behavior Rating Scale for Dementia of the Consortium to Establish a Registry for Alzheimer's Disease, CGI-I, Clinical Global Impression of Improvement, CGI-S Clinical Global Impression of Illness Severity, DIEPSS Drug-Induced Extra-Pyramidal Symptom Scale, DMAS Dementia Mood Assessment Scale, FIM Functional Independence Measure, HAM-A/-D Hamilton Rating Scale for Anxiety/Depression, IADL instrumental activities of daily living by Lawton and Brody, MDS-ADL, Minimum Data Set - Activities of Daily Living, MMSE Mini-Mental State Examination, MOSES Multidimensional Observation Scale for Elderly Subjects, NPI-NH Neuropsychiatric Inventory - Nursing Home Version, OAS Overt Aggression Scale, PSMS Physical Self-Maintenance Scale, SAS Simpson-Angus Scale, SIB Severe Impairment Battery

weeks in patients with severe dementia and BPSD in a psychiatric hospital in Japan [65]. Yokukansan (TJ-54) is part of traditional Japanese herbal medicine and is used to treat insomnia, irritability and neurological disorders such as dementia and AD [66] and may have neuroprotective effects against glutamate-induced excitotoxicity [67]. Yokukansan was used as the control group in the further analysis of the study data. Teranishi et al. also included a small number of patients with vascular dementia (VD) or dementia with Lewy bodies (DLB) [65].

\section{Antipsychotics}

A multicentre, 3-arm RCT compared treatment with flexibly dosed haloperidol, quetiapine or placebo in patients in nursing homes with $\mathrm{AD}$ and psychotic symptoms in 47 investigational sites in the USA for 10 weeks [64].

\section{Anticonvulsants}

Four studies investigating the efficacy and safety of anticonvulsants for aggressive or agitated behaviour in patients with $\mathrm{AD}$, vascular or mixed dementia were included. Three RCTs investigated treatment with carbamazepine [60, 62, 63], while Porsteinsson et al. assessed the use of valproate [61]. Subjects were living in US nursing homes, long-care facilities or with a caregiver.

\section{Excluded studies}

As shown in Fig. 1, most studies were excluded due to missing functional status assessments or because no suitable assessment of physical frailty according to MedQoL criteria was available. Another main reason for exclusion was study populations' average age, lack of a drug intervention or availability as an abstract only. In some of the screened full texts, potentially suitable physical frailty assessments according to MedQoL criteria were reported, but not measured at baseline.

\section{Risk of bias assessment}

Overall, most studies were at unclear or low risk of bias in each of the assessed domains. The only trial with a probable high risk of bias (Tariot et al., 1994 [62]) was not included in the further quantitative analysis, due to high risk of selection bias and insufficient reporting of outcome data. Risk of bias assessment for each domain of the included RCTs is presented in Fig. 2.

\section{Acetylcholinesterase inhibitors}

Two studies investigating the efficacy and safety of AChEI (galantamine, donepezil) were included [57, 58]. All outcomes rated according to GRADE are summarized in an evidence profile (see Additional file 3$)$.

\section{Functional status}

Neither of the trials showed a significant change in functional status as assessed with the MDS-ADL (co-primary outcome in Burns et al.) and PSMS (secondary outcome in Tariot 2001 et al.) [57, 58]. Both intervention and control groups' functional status worsened slightly during the study period. Unfortunately, only one study reported the assessment of physical frailty in a way suitable for data extraction [57]. Therefore, only Burns et al. was included in the rating of the quality of evidence for functional status involving 364 participants (MD - 0.40; 95\% CI: [- 1.32, 0.52]) [57]. The quality of evidence of this outcome according to GRADE was very low. 


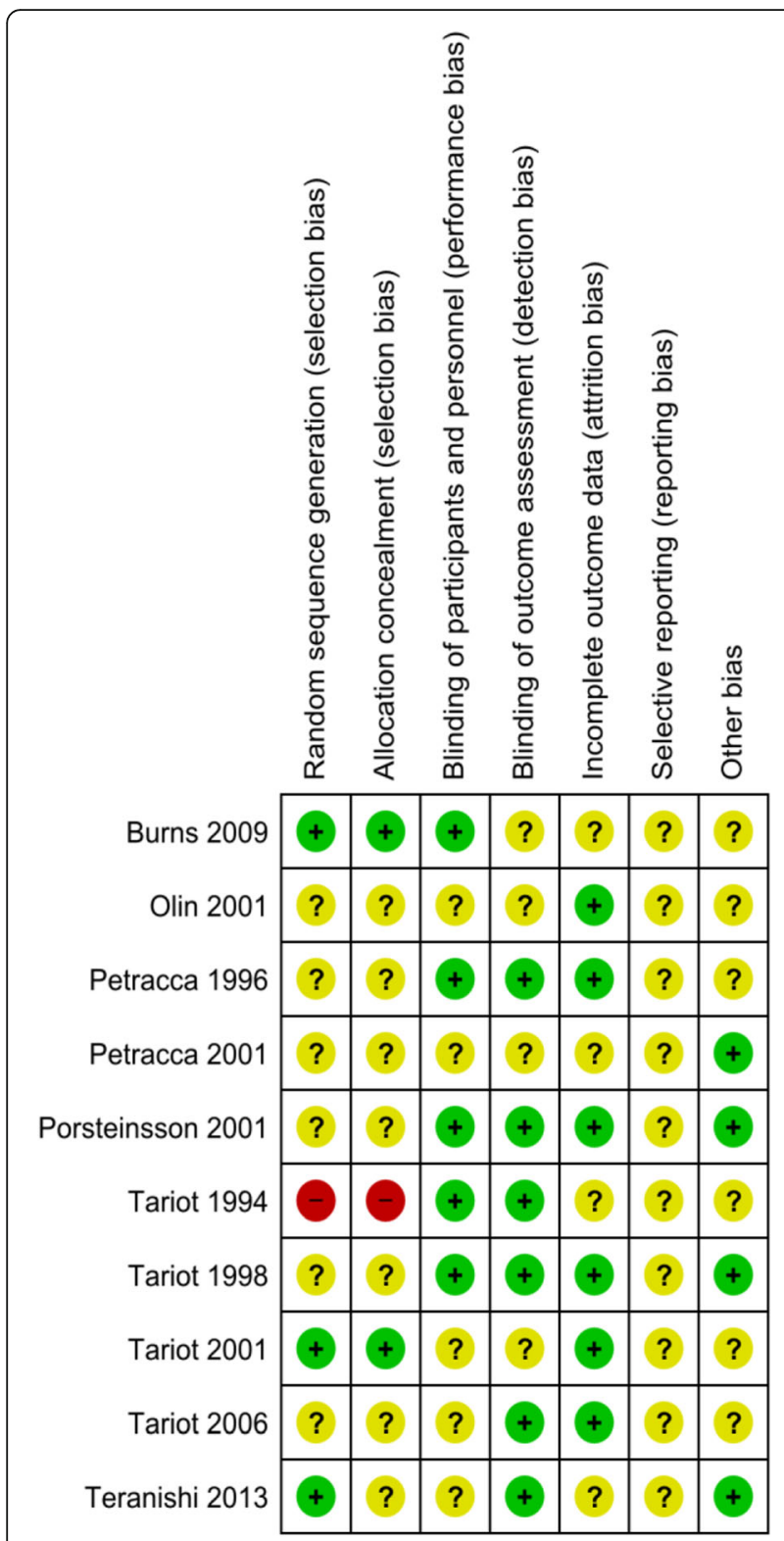

Fig. 2 Risk of bias summary: review authors' judgements about each risk of bias item for each included study

\section{Cognitive function}

When assessing cognitive function, Burns et al. [57] reported a significant difference in cognitive function assessed as a co-primary outcome with the Severe Impairment Battery (SIB) in favour of galantamine over placebo (MD 5.2; 95\% CI: [2.24, 8.16]; Hedges' g $=0.36$ ) [57]. Tariot et al. (2001) [58] did not provide suitable data for extraction, but reported superiority of donepezil compared with placebo as measured with the MiniMental State Examination (MMSE) as a secondary outcome. However, the comparison only reached significance in weeks 8,16 and 20 . In addition, Tariot et al. (2001) [58] reported another secondary outcome, the
Clinical Dementia Rating - Sum of Boxes Score (CDRSoB), which showed a significant difference at the end of the treatment period in favour of donepezil. This difference was mainly due to cognitive worsening in the placebo group [58]. Only data from Burns et al. [57] was suitable for extraction and was used for quality of evidence rating. The quality of evidence of this outcome according to GRADE was very low.

\section{BPSD}

Tariot et al. (2001) measured BPSD as a primary outcome by using the Neuropsychiatric Inventory - Nursing Home Version (NPI-NH), which showed a nonsignificant difference between donepezil and placebo (MD 2.60; 95\% CI: [- 2.67, 7.78]) [58]. There was no significant improvement in either group in the NPI-NH score. The quality of evidence of this outcome according to GRADE was low.

\section{Adverse events}

Both studies reported adverse events (AE) during the treatment period. When pooling data of both studies ( $\mathrm{n}$ = 615) for the total number of AEs, a non-significant difference between AChEI (282/310, 91.0\%) and placebo (279/305, 91.5\%) was shown (RR 1.00; 95\% CI: [0.95, 1.05]; $\left.\mathrm{I}^{2}=0 \%\right)[57,58]$. For gastrointestinal AEs, there was no significant difference between AChEI and placebo (RR 1.17; 95\% CI: [0.83, 1.65]; $\mathrm{I}^{2}=69 \%$ ). In contrast, pooled neurological AEs (agitation, tremor, confusion, depression, aggression, vertigo, abnormal gait, dizziness) occurred significantly more often in the AChEI group (89/310, 28.7\%) than in the placebo group (58/305, 19\%; RR 1.53; 95\% CI: [1.15, 2.03]; $\mathrm{I}^{2}=44 \%$ ). The quality of evidence for the total number of AEs according to GRADE was moderate.

\section{Treatment tolerability}

Treatment tolerability was assessed by using the total number of dropouts as a proxy. The pooled data showed no significant difference between AChEI and placebo (RR 0.87; 95\% CI: $[0.63,1,19] ; \mathrm{I}^{2}=0 \%$ ) $[57,58]$. The quality of evidence of this outcome according to GRADE was very low.

\section{Deaths}

The pooled data for the total number of deaths in both studies $(\mathrm{N}=61)$ indicated that there were significantly fewer deaths in the AChEI group than in the placebo group (RR 0.38; 95\% CI: [0.19, 0.75]; $\mathrm{I}^{2}=0 \%$ ) [57, 58]. The quality of evidence of this outcome was low according to GRADE (Fig. 3). 


\begin{tabular}{|c|c|c|c|c|c|c|c|c|c|c|}
\hline \multirow[t]{6}{*}{ a) } & Study or Subgroup & \multicolumn{2}{|c|}{ AChE inhibitors } & \multicolumn{2}{|c|}{ Placebo } & & $\begin{array}{l}\text { Risk Ratio } \\
\text { M-H, Fixed, } 95 \% \text { Cl }\end{array}$ & \multicolumn{2}{|c|}{$\begin{array}{l}\text { Risk Ratio } \\
\text { M-H, Fixed, } 95 \% \mathrm{Cl}\end{array}$} & \\
\hline & Burns 2009 & 45 & $\begin{array}{r}\text { Total } \\
207\end{array}$ & 23 & 200 & Weight & $1.89[1.19,3.00]$ & & \multirow{2}{*}{$\bar{\square}$} & \\
\hline & Tariot 2001 & 44 & 103 & 35 & 105 & $59.7 \%$ & $1.28[0.90,1.82]$ & & & \\
\hline & Total $(95 \% \mathrm{Cl})$ & & 310 & & 305 & $100.0 \%$ & $1.53[1.15,2.03]$ & & & \\
\hline & Total events & 89 & & 58 & & & & & & \\
\hline & \multicolumn{2}{|c|}{ Test for overall effect: $Z=2.93(P=0.003)$} & & & & & & 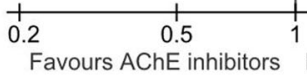 & $\begin{array}{c}2 \\
\text { Favours placebo }\end{array}$ & $\begin{array}{l}+ \\
5\end{array}$ \\
\hline \multirow{7}{*}{ b) } & & \multicolumn{2}{|c|}{ AChE inhibitors } & \multicolumn{2}{|c|}{ Placebo } & & Risk Ratio & \multirow{2}{*}{\multicolumn{3}{|c|}{$\begin{array}{c}\text { Risk Ratio } \\
\text { M-H, Fixed, } 95 \% \mathrm{Cl} \\
\end{array}$}} \\
\hline & Study or Subgroup & Events & Total & Events & Total & Weight & M-H, Fixed, $95 \% \mathrm{Cl}$ & & & \\
\hline & Burns 2009 & 8 & 207 & 21 & 200 & $75.1 \%$ & $0.37[0.17,0.81]$ & $\square$ & & \\
\hline & Tariot 2001 & 3 & 105 & 7 & 103 & $24.9 \%$ & $0.42[0.11,1.58]$ & & & \\
\hline & Total $(95 \% \mathrm{Cl})$ & & 312 & & 303 & $100.0 \%$ & $0.38[0.19,0.75]$ & & & \\
\hline & Total events & 11 & & 28 & & & & & & \\
\hline & \multicolumn{7}{|c|}{$\begin{array}{l}\text { Heterogeneity: } \mathrm{Chi}^{2}=0.03, \mathrm{df}=1(P=0.87) ;\left.\right|^{2}=0 \% \\
\text { Test for overall effect: } Z=2.79(P=0.005)\end{array}$} & $\begin{array}{cccc}0.1 & 0.2 & 0.5 & 1 \\
\text { Favours } & \text { AChE inhibitors }\end{array}$ & 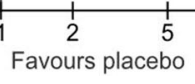 & 10 \\
\hline \multicolumn{11}{|c|}{$\begin{array}{l}\text { Fig. } 3 \text { Forest plots of AChEl neurological AEs and deaths by Tariot et al. [58] and Burns et al. [57]. a Forest plot of the pooled neurological } \\
\text { adverse events in Burns et al. and Tariot et al. b Forest plot of the pooled number of deaths in Burns et al. and Tariot et al. } 95 \% \mathrm{Cl}=95 \% \\
\text { confidence interval; } \mathrm{AChE-I}=\text { acetylcholinesterase inhibitor; } \mathrm{Ch}^{2}=\mathrm{Chi}^{2} \text { test value to evaluate heterogeneity; } \mathrm{df}=\text { degrees of freedom; fixed }= \\
\text { fixed effects model; } \mathrm{I}^{2}=\mathrm{I}^{2} \text { test value to evaluate heterogeneity; IV = inverse variance; } \mathrm{MD}=\text { mean difference; } \mathrm{M}-\mathrm{H}=\text { relative risk by Mantel- } \\
\text { Haenszel; Neurolog. AEs = neurological adverse events; } \mathrm{SD}=\text { standard deviation }\end{array}$} \\
\hline
\end{tabular}

\section{Antidepressants}

Three RCTs investigating the efficacy and safety of antidepressants (clomipramine, fluoxetine, fluvoxamine) were included $[56,59,65]$. Unfortunately, one cross-over trial only reported outcomes graphically and statistical data were not suitable for extraction, except for data of $\mathrm{AE}$ data, that were included in the quantitative analysis [59]. None of the studies reported the number of deaths during the study period. All outcomes rated according to GRADE are summarized in evidence profiles (see Additional file 4).

\section{Functional status}

There was no significant difference between antidepressant and placebo/yokukansan in any of the studies as assessed by the Functional Independence Measure (FIM) as a secondary outcome. Petracca et al. (2001) reported no significant difference between fluoxetine and placebo (MD 2.70; 95\% CI: [- 0.51, 5.91]); the quality of evidence of this outcome according to GRADE was low [56]. Teranishi et al. also showed no significant difference between fluvoxamine and yokukansan (MD - 7.71; 95\% CI: $[-24.33,8.91])$; the quality of evidence of this outcome according to GRADE was low [65].

\section{Cognitive function}

Both Teranishi et al. and Petracca et al. (2001) reported a non-significant difference between fluoxetine/fluvoxamine and placebo/yokukansan, for the secondary outcome as assessed by the Mini-Mental State Examination (MMSE) (fluoxetine: MD - 0.8, 95\% CI: [- 4.8, 3.2]; fluvoxamine: $\mathrm{MD}$ - 0.63, 95\% CI: [- 3.34; 2.17]) [56, 65].
The quality of evidence of both outcomes according to GRADE was very low.

Petracca et al. (1996) reported non-significant changes in MMSE scores in the first treatment period: the clomipramine group showed a small improvement $(\sim 0.2$ pt.), while the placebo group worsened by about $0.5 \mathrm{pt}$. in the MMSE [59]. Data was not suitable for extraction and was therefore not included in quantitative analysis and quality of evidence rating.

\section{BPSD}

Petracca et al. (2001) assessed BPSD with the Hamilton Rating Scale for Depression (HAM-D), as a primary outcome, and the Hamilton Rating Scale for Anxiety as a secondary outcome (HAM-A). Neither outcome measure showed significant differences between fluoxetine and placebo (MD HAM-A 0.80; 95\% CI: [- 2.39, 3.99]) (MD HAM-D - 0.6; 95\% CI: [- 3.99, 2.79]) [56]. Teranishi et al. showed no significant difference in the primary outcome of general BPSD symptoms assessed with the NPI-NH between fluvoxamine and yokukansan (MD - 2.16; 95\% CI: [- 9.44, 5.12]) [65]. The quality of evidence of both outcomes according to GRADE was very low.

\section{Clinical global impression}

Petracca et al. (2001) reported the Clinical Global Impression - Improvement scale (CGI-I) scale as a continuous outcome $(1=$ very much improved; $7=$ very much worsened). This primary outcome did not show significant differences between fluoxetine and placebo (MD - 0.30; 95\% CI: [- 0.76, 0.16]) [56]. 


\section{Adverse events}

The pooled data from Petracca et al. (1996) and Petracca et al. (2001) showed that AEs were more frequent in patients treated with antidepressants $(15 / 28,53.6 \%)$ than in the placebo group (12/34, 35.3\%); however, this finding did not reach significance (RR 1.31; 95\% CI: [0.82, 2.09]; $\left.\mathrm{I}^{2}=0 \%\right)[56,59]$. Teranishi et al. also showed no significant difference between fluvoxamine and yokukansan regarding the total number of adverse events (RR 1.11; 95\% CI: [0.8, 1.52]) [65]. Both outcomes' quality of evidence according to GRADE was very low.

Teranishi et al. also assessed extra-pyramidal symptoms by the Drug-Induced Extra-Pyramidal Symptoms Scale (DIEPSS), which showed no significant difference between fluvoxamine and yokukansan (MD 0.15; 95\% CI: $[-0.22,0.52])[65]$.

\section{Treatment tolerability}

The data from Petracca et al. (1996) and Teranishi et al. showed no significant differences in treatment tolerability for the comparison of antidepressants with placebo and yokukansan, respectively, as assessed by total numbers of dropouts (fluoxetine: RR 0.71, 95\% CI: [0.15, 3.43]; fluvoxamine: RR 0.96, 95\% CI: $[0.15,6.37]$ ) [56, 65]. The quality of evidence of these outcomes according to GRADE was very low.

Petracca et al. (1996) ( $\mathrm{N}=24)$ did not report dropouts separately for each treatment period but reported two dropouts in the placebo group and one dropout during clomipramine treatment [59].

\section{Anticonvulsants}

Four RCTs investigating the efficacy and safety of anticonvulsants (carbamazepine, valproate) in frail older patients with $\mathrm{AD}$ and aggressive/agitated behaviour were included [60-63]. One small cross-over trial was not included in the quantitative analysis due to high risk of bias and insufficient reporting of statistical outcome data [62]. All outcomes rated according to GRADE are summarized in an evidence profile (see Additional file 5).

\section{Functional status}

All four studies assessed functional status by the Physical Self-Maintenance Scale, an ADL scale, as a secondary outcome. There was no significant difference in PSMS scores between anticonvulsants and placebo (MD 0.44; 95\% CI: $\left.[-0.33,1.22] ; \mathrm{I}^{2}=0 \%\right)[60,61,63]$. The quality of evidence of this outcome was very low.

Also, the instrumental activities of daily living (IADL), which were assessed by Olin et al., showed no significant difference between carbamazepine and placebo (MD 0.40 ; $95 \%$ CI: $[-1.5,2.3])[60]$.

\section{Cognitive function}

The pooled data of three RCTs showed no significant differences between anticonvulsants and placebo in the secondary outcome of cognitive function assessed by the MMSE (MD 0.02; 95\% CI: [- 1.44, 1.47]; $\mathrm{I}^{2}=$ $0 \%)[60,61,63]$. The quality of evidence of this outcome was low. Tariot et al. (1994) also reported no significant differences in the MMSE between anticonvulsant and placebo [62].

\section{BPSD}

The total score of the Brief Psychiatric Rating Scale (BPRS), which was reported by three RCTs as the primary outcome, showed no significant difference between anticonvulsants and placebo (MD - 3.02; 95\% CI: $\left.[-7.62,1.57] ; \mathrm{I}^{2}=69 \%\right)[60,61,63]$. The quality of evidence of this outcome was assessed as very low. However, two RCTs reported a significant reduction of the BPRS agitation factor in the group treated with anticonvulsants (MD - 2.07; 95\% CI: [- 3.54, - 0.60]; $\left.\mathrm{I}^{2}=56 \%\right)[61,63]$. In addition, another two RCTs showed a significant reduction in the hostility factor of the BPRS in participants treated with carbamazepine (MD - 1.77; 95\% CI: [- 2.54, - 0.99]; $\left.\mathrm{I}^{2}=0 \%\right)$ $[60,63]$. When the carbamazepine data were pooled with valproate data from the study by Porsteinsson et al., the difference was no longer significant (MD 1.21; $95 \%$ CI: [- 2.47, 0.05]; $\mathrm{I}^{2}=72 \%$ ) [61].

The Overt Aggression Scale (OAS), which was used in two RCTs as a secondary outcome, showed no significant difference in between anticonvulsants and placebo (MD - 2.36; 95\% CI: [- 7.16, 2.45]; $\left.\mathrm{I}^{2}=74 \%\right)[61,63]$. Tariot et al. (1994) also reported no significant difference between carbamazepine and placebo as measured by the OAS [62].

Furthermore, secondary outcome measures for BSPD, such as the HAM-D in Olin et al. and the CohenMansfield Agitation Inventory (CMAI) in Porsteinsson et al., showed no significant differences for the comparison between anticonvulsants and placebo (CMAI: MD 2.20, 95\% CI: [- 11.60, 7.20]; HAM-D: MD - 2.80, 95\% CI: $[-6.17,0.57])[60,61]$. The Dementia Mood Assessment Scale (DMAS), which was used in Tariot et al. (1994) as a secondary outcome, also showed no significant difference between carbamazepine treatment and placebo [62].

\section{Clinical global impression}

All three RCTs included in quantitative analysis reported the clinical global impression (CGI-I) [60, 61, 63]. Olin et al. and Tariot et al. (1998) did report the CGI as a primary outcome, but Porsteinsson et al. did not specifically describe the CGI as a primary or secondary outcome. However, when including the data of 
Porsteinsson et al. the pooled outcome remained nonsignificant. This outcome was analysed as a dichotomous outcome and adjacent categories were combined into two groups: "worsening/no change" and "improvement". The number of events equated to the number of participants whose clinical impression improved. The CGI-I showed no significant difference between treatment with anticonvulsants and placebo (RR 1.72; 95\% CI: [0.76, 3.90]; $\mathrm{I}^{2}=76 \%$ ).

\section{Adverse events}

When pooling data of three RCTs with carbamazepine, there were more AEs in participants treated with anticonvulsants $(39 / 64,60.9 \%)$ than treated with placebo (24/64, 37.5\%), but this difference did not reach significance (RR 1.49; 95\% CI: $\left.[0.76,2.93] ; \mathrm{I}^{2}=67 \%\right)[60,61$, 63]. The quality of evidence of this outcome according to GRADE was very low. For valproate, Porsteinsson et al. reported significantly more valproate-treated participants with AEs $(19 / 28,67.9 \%)$ than placebo $(9 / 28$, 32.1\%; RR 2.11; 95\% CI: [1.16, 3.83]) [61].

Pooled data of the total number of serious and clinically significant AEs suggested an increased risk for AEs among those taking anticonvulsants (anticonvulsants 7/ 55, 12.7\%; placebo $1 / 52,0.02 \%$; RR 4.81; $95 \%$ CI: [0.87, 26.56]; $\mathrm{I}^{2}=0 \%$ ) $[61,63]$. Other trials did not report the total number of serious and clinically significant AEs $[60,62]$.

Two studies reported data on movement disorders (ataxia, postural instability, involuntary movement) and falls and showed a significant difference in favour of placebo (events on anticonvulsants: 42/55, 76.3\%; events on placebo 26/52, 50\%; RR 1.49; 95\% CI: [1.13, 1.97]; $\mathrm{I}^{2}=$ $0 \%)[61,63]$.

\section{Treatment tolerability}

All included studies reported the total number of dropouts $[60,61,63]$. Most of the dropouts in the placebo group were reported to be due to worsening of agitation and aggressive behaviour. There was no significant difference in treatment tolerability as assessed by the number of dropouts (anticonvulsants 7/63, 11.1\%; placebo 8/ 64, 12.5\%; RR 0.94; 95\% CI: [0.36, 2.47]; $I^{2}=49 \%$ ). The quality of evidence of this outcome was assessed as very low.

\section{Death}

Tariot et al. (1994) reported one death during the carbamazepine treatment period [62]. No other study reported any deaths.

\section{Antipsychotics}

Two 3-arm studies investigating the efficacy and safety of antipsychotics were included in this review. Tariot et al. compared quetiapine and haloperidol with placebo in frail older patients with $\mathrm{AD}$ and psychotic symptoms [64]. Teranishi et al. compared risperidone with the Chinese herbal medicine yokukansan and fluvoxamine in AD patients with general BPSD [65]. Treatment effects of fluvoxamine are reported in the antidepressant section above. Due to different comparisons (placebo/ yokukansan) and study populations (psychotic symptoms/general BPSD), separate evidence profiles were created. All rated outcomes according to GRADE are summarized in evidence profiles (see Additional file 6).

\section{Functional status}

Tariot et al. (2006) assessed functional status using the PSMS as a secondary outcome, which showed a significant worsening in subjects treated with haloperidol compared with placebo (MD 1.12; 95\% CI: [0.33, 1.191]; Hedges' $\mathrm{g}=0.42)$, even though the mean daily dose (1.9 $\mathrm{mg} /$ day $)$ and the median maximum dose $(2.0 \mathrm{mg} /$ day $)$ were below the potentially inappropriate dose of $>2 \mathrm{mg} /$ day as indicated in the PRISCUS list [34, 64]; in contrast, no significant decrease in functional status for quetiapine compared with placebo was shown (MD - 0.48; 95\% CI: [- 1.33, 0.37]) [64]. Teranishi et al. also reported no significant changes in functional status (secondary outcome) as assessed with the FIM when comparing risperidone and placebo (MD - 1.15; 95\% CI: [- 17.08, 14.78]) [65]. The quality of evidence of all outcomes regarding functional status according to MedQoL criteria was rated as very low.

In Tariot et al. (2006), the secondary outcome Multidimensional Observation Scale for Elderly Subjects (MOSES) - Social activities subscale also showed a significant worsening in subjects treated with haloperidol compared with placebo (MD 1.43; 95\% CI: $[0.18,2,68]$ ). Quetiapine-treated patients showed no significant differences in MOSES scores compared with placebo (MD 0.07; 95\% CI: [- 1.49, 1.35]) [64].

\section{Cognitive function}

None of the studies showed a significant difference in the secondary outcome, assessed with the MMSE scores when comparing antipsychotics and placebo/yokukansan (control groups) (haloperidol: MD - 0.16, 95\% CI: [1.63, 1.31]; quetiapine: $\mathrm{MD}-0.68,95 \% \mathrm{CI}:[-1.92$, 0.56]; risperidone: $\mathrm{MD}-0.47$; $95 \% \mathrm{CI}$ : [- 3.04, 2.10]) $[64,65]$. The quality of evidence for quetiapine and haloperidol was low, and the quality of evidence for risperidone was rated as very low.

\section{BPSD}

Even though Tariot et al. (2006) did not find any statistically significant changes in the primary outcome of total BPRS scores when comparing quetiapine and 
haloperidol with placebo ${ }^{2}$, analysis of the agitation factor subscale showed a significant improvement in subjects treated with quetiapine or haloperidol compared with placebo (haloperidol: MD - 1.41, 95\% CI: [- 2.47, 0.35]; quetiapine: $\mathrm{MD}-1.18,95 \% \mathrm{CI}$ : [- 2.26, - 0.10]) [64]. In contrast, the BPRS anergia subscale showed no significant difference when comparing quetiapine and placebo (MD 0.40; 95\% CI: [- 0.49, 1.29]), but there was a statistically significant worsening in the haloperidol group when compared with placebo-treated subjects (MD 1.94; 95\% CI: $[0.99,2.89]$ ). Another subscale analysis of the BPRS, thought disturbances, showed no statistically improvement or worsening when comparing antipsychotics with placebo (haloperidol: MD - 0.31, 95\% CI: [- 1.22, 0.60]; quetiapine: MD - 0.43; 95\% CI: $[-1.36,0.50])$.

Additionally, Tariot et al. (2006) administered the NPI-NH as a secondary outcome and found a significant improvement in the NPI-NH total score in subjects treated with haloperidol compared with placebo (MD 1.82; 95\% CI: [- 3.51, - 0.13]). Quetiapine showed no significant difference in the NPI-NH total score compared with placebo (MD - 0.03; 95\% CI: [- 1.79, 1.73]) [64]. Both quetiapine and haloperidol showed nonsignificant improvements in the NPI-NH agitation subitem analysis for antipsychotics compared with placebo (haloperidol: MD - 0.94, 95\% CI: [- 2.23, 0.35]; quetiapine: MD - 1.14; 95\% CI: [- 2.51, 0.23]). Teranishi et al. used the NPI-NH as the primary outcome to measure BPSD and reported no significant differences in the NPI-NH total score when comparing risperidone and yokukansan (MD 2.72; 95\% CI: [- 3.34, 8.87]) [65].

The quality of evidence for BPSD as assessed with the $\mathrm{NPI}-\mathrm{NH}$ was low for quetiapine and haloperidol, and the quality of evidence for risperidone was rated as very low according to GRADE.

\section{Clinical global impression}

Tariot et al. (2006) found no statistically significant differences in the primary outcome of clinical global impression of illness severity score comparing quetiapine and haloperidol with placebo (quetiapine: MD - 0.13, 95\% CI: [- 0.42, 0.16]; haloperidol: MD - 0.05, 95\% CI: $[-0.33,0.23])$ [64].

\section{Adverse events}

Tariot et al. (2006) used the Abnormal Involuntary Movement Scale (AIMS) and the Simpson-Angus Scale (SAS) to assess extrapyramidal symptoms, but none of those showed any significant differences between quetiapine and placebo (AIMS: MD 0.12, 95\% CI: [- 0.56,

${ }^{2}$ Haloperidol: MD - 0.39; 95\% CI: [- 3.43, 2.65]. Quetiapine: MD 2.32; 95\% CI: [- 5.41, 0.77]
0.80]; SAS: MD 0.00, 95\% CI: [- 1.14, 1.14]). In contrast, Tariot et al. (2006) found a significant worsening in extrapyramidal symptoms as assessed with the SAS in subjects treated with haloperidol compared with placebo (MD 2.72; 95\% CI: $[1.36,4.08]$ ) and a nearly significant difference in the AIMS score compared with placebo (MD 0.58; 95\% CI: [- 0.10, 1.26]) [64]. The quality of evidence regarding extrapyramidal symptoms assessed with the SAS for haloperidol and quetiapine was low and very low, respectively.

Teranishi et al. also assessed extrapyramidal symptoms by using the Drug-Induced Extra-Pyramidal Symptoms Scale (DIEPPS), which showed a significant worsening in risperidone treated subjects compared with yokukansan (MD 0.87; 95\% CI: [0.43, 1.31]) [65]. The quality of evidence for this outcome was rated as low.

Both studies reported on AEs and severe AEs. Teranishi et al. did not find any statistically significant differences between risperidone and yokukansan in the total number of AEs (RR 1.20; 95\% CI: [0.90, 1.61]) and serious adverse events (SAE; as described by the authors as fall with contusion, oversedation, swallowing difficulty, stridor or sudden death; RR 1.73; 95\% CI: $[0.46,6.52])$ [65]. Tariot et al. (2006) also found no significant differences between haloperidol/quetiapine and placebo in the total number of severe AEs (haloperidol: RR 1.30, 95\% CI: $[0.64,2,64]$; quetiapine: RR 0.90, 95\% CI: $[0.41,1.98])$ [64]. In addition, the total number of falls and fractures in subjects treated with antipsychotics were not significantly different to placebo/yokukansan (haloperidol: RR $0.98,95 \% \mathrm{CI}:[0.76,1.44], \mathrm{P}=0.93$; quetiapine: RR 0.86 , 95\% CI: [0.57, 1.29]; risperidone: RR 0.52, 95\% CI: [0.05, 5.39]). However, the further analysis of certain AEs found some significant differences between antipsychotics and placebo: neurological AEs, such as somnolence, agitation, abnormal gait, insomnia and convulsion were significantly more frequent in subjects treated with haloperidol $(62 / 94,65.9 \%)$ than in the placebo group (29/98, 29.6\%; RR 2.23, 95\% CI: [1.59, 3.13]). Furthermore, Tariot et al. (2006) reported significantly more infections (not further specified) in the quetiapine group $(13 / 91,14.3 \%)$ than in the placebo group $(5 / 98,5.1 \%$; RR $2.69,95 \%$ CI: [1.00, 7.23]).

\section{Treatment tolerability}

Neither study showed significant differences in dropout rates when comparing antipsychotics with placebo/yokukansan (haloperidol: 39/94, 41.5\%; RR 1.14, 95\% CI: [0.80, 1.63]; quetiapine: 29/91, 31.9\%; RR 0.88, 95\% CI: $[0.59,1.30]$; risperidone: $2 / 28,7.1 \%$; RR $1.93,95 \%$ CI: [0.19, 20.05]; placebo: 36/99, 36.4\%; yokukansan: $1 / 27$, $3.7 \%)[64,65]$. The quality of evidence of this outcome was very low for all interventions according to GRADE. 


\section{Deaths}

There were also no statistically significant findings regarding the total number of deaths during the study period (haloperidol: 7/94, 7.4\%; RR 1.82, 95\% CI: [0.55, 6.03]; quetiapine: $2 / 91,2.2 \%$; RR 0.54, 95\% CI: [0.10, 2.87]; risperidone: $1 / 27,3.7 \%$; RR 3.0, 95\% CI: [0.13, 70.53]; placebo: 4/98, 4.1\%; yokukansan: 0/27, 0\%) [64, 65]. The quality of evidence of this outcome according to GRADE was very low for all interventions.

\section{Discussion}

This systematic review evaluated the efficacy and safety of pharmacotherapy for AD and BPSD in frail older patients. Despite the increasing number of publications on frailty $[19,68]$ and the call by several institutions to include more frail older patients in clinical trials [11, 31], only ten eligible studies, mainly of small study population size, were identified. Many of the screened studies were excluded due to a lack of functional status assessment or frailty evaluation, and it was therefore not possible to classify included patients as frail or non-frail. However, we were able to identify two RCTs focusing on AChEIs, four on anticonvulsants, one on antipsychotics, two on antidepressants, and one triple-arm study investigating one antidepressant and one antipsychotic medication. Unfortunately, quality of life (QoL), which is considered an important outcome in $\mathrm{AD}$ trials by the EMA, was not assessed in any of the included studies [44]. For all outcomes of the included RCTs quality of evidence was mostly of (very) low quality, mainly due to the small study size. Overall, the small number of eligible studies identified in our literature review is in line with previous publications showing that frail elderly patients are often underrepresented in clinical trials [6971].

In general, our systematic review suggested minimal positive effects of pharmacotherapy for $\mathrm{AD}$ and associated BPSD, and indicated possible harms with some treatments. Our data analysis suggested that frail older patients treated with AChEIs had slight improvements in cognition and that AChEIs were generally tolerated well in frail older patients. Antidepressants did not show any significant improvements in depressive symptoms or BPSD in general but were well-tolerated. RCTs of anticonvulsants showed some significant improvement in certain BPSD items (hostility, agitation), but no significant reduction of total BPSD scores. Antipsychotics, especially haloperidol, showed some significant efficacy on certain BPSD items (anergia, agitation) and NPI-NH total score, but showed no effect on clinical global impression ratings.

There were also possible negative treatment effects shown in frail older patients. Haloperidol-treated subjects scored significantly worse in ADLs and experienced more neurological AEs. Furthermore, haloperidol- and risperidone-treated frail older patients experienced significantly more EPMS and significantly more falls and fractures. Furthermore, there were significantly more falls and movement disorders in anticonvulsant-treated frail older patients and a significantly higher number of valproate-treated patients who experienced at least one AE.

\section{Acetylcholinesterase inhibitors}

We reviewed 2 studies of AChEIs by Tariot et al. (2001) and Burns et al. $[57,58]$. In both studies, it was planned to treat patients with the recommended maximum dose if possible; average daily doses were above the minimum effective daily dose. Neither trial showed significant changes in functional status as assessed with ADL measures (MDS-ADL, PSMS) when comparing AChEIs with placebo. These findings contrast with those of larger meta-analyses of AChEI in AD by the Cochrane Collaboration and the IQWiG, which indicated that AChEs showed significant superiority over placebo treatment regarding ADL; however, these studies did not specifically focus on frail older patients [72, 73]. The efficacy of donepezil in the treatment of BPSD in younger patients is also debatable: A Cochrane review [74] from 2006 of donepezil treatment in patients with $\mathrm{AD}$ found only small significant effects of donepezil on BPSD, and a review by the IQWiG of donepezil treatment in patients with AD showed no relevant benefit of donepezil [73]. Tariot et al. (2001) also found no significant treatment effect of donepezil on BPSD [58]. The small magnitude of the treatment effect regarding cognitive function in Burns et al. [57] (Hedges' $g=0.36$ ) was similar to previous studies with other AChEIs in severe AD in younger patients $[75,76]$.

Importantly, in the two included studies, there were significantly fewer deaths in the AChEI groups than in the placebo groups. Even if the quality of evidence was low-mainly due to the small number of participantsreduced mortality for $\mathrm{AD}$ patients treated with AChEIs has also been shown in previous systematic reviews evaluating efficacy, safety and cardiovascular outcomes in $\mathrm{AD}$ patients treated with $\mathrm{AChEI}$ involving larger patient numbers $[77,78]$. The decreased mortality in other studies was mainly accounted for by a reduction in cardiovascular events [79]. This finding is of questionable benefit in frail older populations, as life extension is usually not a treatment aim and subjective well-being and other palliative care goals are more desirable.

A Cochrane review evaluating efficacy and safety of AChE inhibitors in AD patients, which did not specifically focus on frail older patients, indicated significantly more dropouts and adverse events in subjects treated with AChEIs [72]. In contrast, the two studies we 
analysed suggested that according to MedQoL criteria treatment with AChEIs was generally well tolerated in frail older patients. These findings with respect to total number of AEs are somewhat reassuring, since frail older patients might have been expected to be more vulnerable to adverse effects than younger patient populations in other $\mathrm{AD}$ clinical trials $[10,14,15]$. However, neurological AEs (agitation, tremor, confusion, depression, aggression, vertigo, abnormal gait, dizziness) were significantly more frequent in patients receiving AChEIs.

\section{Antidepressants}

We found two RCTs investigating antidepressants (clomipramine, fluoxetine) in patients with $\mathrm{AD}$ and depression [56, 59]. One 8-week RCT also investigated the antidepressant fluvoxamine compared with yokukansan in patients with severe $\mathrm{AD}$, vascular dementia and dementia with Lewy bodies and general BPSD in a Japanese psychiatric hospital [65].

In the included RCTs, there was no significant improvement in depressive symptoms/BPSD in frail older patients. In younger $\mathrm{AD}$ patients, the current evidence generally supports the use of antidepressants (i.e. SSRIs for treatment of depression [80]); however, evidence for their efficacy in AD-related BPSD is contradictory [56, 59, 65]. A Cochrane review from 2018 of depression in dementia that did not specifically focus on frail older patients showed no significant difference in reduction of depression scores between antidepressant and placebo, but significant superiority of antidepressants in depression remission rates [81]. A systematic review of antidepressants in BPSD found some efficacy of antidepressants in the treatment of BPSD [82]. These differences could be due to the heterogeneity in patient populations and the use of different antidepressants. In terms of functional status and cognition, none of the three studies of antidepressants included in our systematic review showed significant benefits in functional status or cognitive function compared with placebo or yokukansan. This result is in line with a Cochrane review of antidepressants in AD from 2018, which also did not show a cognitive or functional benefit of antidepressants [81]. However, some smaller reviews have found that antidepressants (other than tricyclics, which could decrease cognitive function [83]) may reduce cognitive decline in the course of AD [84, 85]. The duration of included studies was probably too short to detect any protective effects on cognition.

All three studies indicated that antidepressants were generally well tolerated, although the number of patients was too small to draw firm conclusions. A similar result was obtained in a systematic review including five studies of antidepressants in AD [83]. In contrast, a larger meta-analysis from 2018 including a total of $1592 \mathrm{AD}$ patients found a significantly higher number of AEs and discontinuations in patients treated with antidepressants than with placebo [81]. Given the unclear state of the evidence, an individual benefit-risk assessment and the preferred use of non-pharmacological interventions is recommended.

\section{Anticonvulsants}

Taken together, the four studies included in our review did not provide clear evidence of the effect of anticonvulsants on BPSD. When all 3 studies with carbamazepine were included, the effect on agitation and hostility remained significant in favour of carbamazepine. However, when the valproate study was included, neither the findings for BPRS nor hostility remained significant. This result is in line with a meta-analysis of valproate, which also found no significant treatment effect in patients with AD [86]. However, there remains the possibility that carbamazepine is effective in agitated and aggressive behaviour in patients with dementia [87, 88]. The evidence is complicated by heterogeneity when data from the four studies were pooled, as there were relevant differences in the study treatments (carbamazepine vs. valproate) and in the patient populations (e.g. Olin et al. included patients who had treatment-resistant symptoms when previously treated with antipsychotics) [60].

The four studies we reviewed showed no significant worsening in cognition over the course of treatment [89, 90]. Conversely, a study in non-frail patients demonstrated more rapid cognitive deterioration and increased brain atrophy in long-term use of valproate in patients with AD [91].

There were significantly more patients treated with valproate who experienced at least one adverse event in comparison with placebo [61]. Other reviews of pharmacotherapy of agitation and aggression in dementia with anticonvulsants have come to similar conclusions [87, 92]. While Tariot et al. (1998) had significantly more adverse events in the carbamazepine group, Olin et al. showed no significant difference between the carbamazepine and placebo groups $[60,63]$. This may be due to the higher average age of participants in Tariot et al. (1998), but given the small study size, this cannot be definitively determined [63]. Furthermore, pooled data of movement disorders and falls showed significantly more events in participants treated with anticonvulsants compared with placebo $[61,63]$. Two other reviews regarding the use of antiepileptic drugs in older patients also showed an association between anticonvulsant treatment and falls in older patients $[93,94]$.

It is not possible to make specific recommendations regarding the use of anticonvulsants in frail older patients with dementia and aggressive/agitated behaviour. Potential adverse outcomes should be carefully evaluated 
when the use of carbamazepine is considered [95]. At least theoretically, treatment with anticonvulsants might allow reduction in the use of antipsychotics, which are also often used in agitated and aggressive dementia patients and have their own set of problems [96, 97]. Further studies are urgently needed.

\section{Antipsychotics}

In the study by Tariot et al. 2006, both quetiapine and haloperidol showed small but significant reductions in the BPRS agitation factor scores compared with placebo (haloperidol Hedges' $\mathrm{g}=0.39$, quetiapine Hedges' $\mathrm{g}=$ 0.32). Haloperidol was also shown to have a small but significant superiority over placebo in reduction of the NPI-NH total score (Hedges' $g=0.31$ ) [64]. Other systematic reviews of atypical antipsychotics and haloperidol in dementia have also shown a small but significant reduction of agitated behaviour after treatment with atypical antipsychotics [98] and a reduction of aggressive behaviour after treatment with haloperidol [99] (Hedges' $g \geq 0.2$ ). The effect of the antipsychotic treatment on the overall clinical picture appears to be minimal. In Teranishi et al., there were no significant changes in overall BPSD between risperidone and yokukansan [65]. This could be due to lack of efficacy, or also due to the heterogenous study population, which in addition to patients with $\mathrm{AD}$ also included participants with dementia with Lewy bodies, vascular dementia and severe dementia (average MMSE 5 pt.).

Even though none of the included studies showed significant changes in cognitive function, there are a few studies that have reported a negative impact of antipsychotics on cognitive function in AD patients [100-102]. However, any cognitive decline due to antipsychotic treatment in the study by Tariot et al. 2006 was of smaller magnitude than reported in other clinical trials [103], and psychotic symptoms themselves seem to be generally associated with more rapid cognitive deterioration in AD [104, 105]. Causality therefore cannot be established.

In terms of adverse events, previous studies in dementia patients have shown that haloperidol and risperidone are associated with more frequent and severe EPMS [98, 99, 102]; haloperidol may be more problematic for dementia patients than risperidone [106, 107]. Including both studies in frail older patients according to MedQoL criteria, we found significant differences in EPMS scores for haloperidol- and risperidone-treated subjects [64, 65]. There was also a significant worsening in functional status in frail older subjects treated with haloperidol [64]. Overall, Tariot et al. (2006) reported significantly more neurological adverse events in haloperidol-treated patients than in patients treated with placebo or quetiapine [64]. However, current evidence also shows that even patients with dementia and $\mathrm{AD}$ treated with atypical antipsychotics, which were not specifically classified as frail, have significantly higher numbers of neurological adverse events in comparison with placebo [98, 102].

Treatment tolerability assessed by on the basis of the total number of dropouts suggested that antipsychotics were well-tolerated, and no significant higher number of deaths in included frail older patients was found.

In contrast, larger RCTs and meta-analyses have shown a significantly higher rate of cerebrovascular events, dropouts and deaths for patients with dementia treated with antipsychotics [99, 102, 108-110], although increased mortality may not be significant when confounding factors such as age, cognitive impairment and the occurrence of BPSD are taken into consideration $[111,112]$. The number of participants in the included studies was probably not sufficient to show those negative treatment effects.

Due to the small number of studies and the small study populations, all outcomes' quality of evidence was rated as low to very low according to GRADE. Known adverse effects of antipsychotics (EPMS, infection, possible cognitive decline) were also demonstrated in the two studies we evaluated. Antipsychotics should be avoided if possible according to the Beers' criteria [113]. Therefore, antipsychotics may also be inappropriate for the use in frail older patients. According to German national guidelines, due to the unfavourable side effect profile, antipsychotics should only be used in severe BPSD when non-pharmacological interventions are not sufficient. Their use should be re-evaluated on a regular basis [114], because some evidence suggests that discontinuation may not significantly worsen BPSD and may decrease the risk of mortality $[115,116]$.

\section{Strengths and limitations}

To our knowledge, this is the first systematic review of RCTs regarding drug therapy of AD and BPSD in frail older patients. In an exhaustive literature research, approximately 45,000 records were screened. Unfortunately, only ten studies were eligible for inclusion in this review, and most of them had only small numbers of patients. Most RCTs did not list any data about functional status or frailty, so that it was not possible to ascertain whether study patients met our inclusion criteria. Because of the small number of eligible RCTs, quality of evidence according to GRADE was mostly (very) low. Therefore, no specific treatment recommendations can be made.

We excluded physical frailty assessments that consisted mainly of cognitive items, because some assessments, such as the ADL, could also indicate impairment in severe dementia even if there was no clear physical frailty. However, some patients with physical frailty 
could also have been inadvertently excluded. Furthermore, despite our attempt to use only "non-cognitive" functional measures to assess frailty, cognition might have also have had an indirect impact on the assessments. This might especially apply to later stages of $\mathrm{AD}$, when motor function could potentially also be affected.

One of the difficulties in our research was reliably identifying studies that included physically frail patients, because physical frailty assessments are seldom performed or reported in RCTs. It is possible that frail patients were included in some additional studies, but that their data were not reported separately, thereby obscuring the effects of pharmacotherapy on this specific group. In future RCTs in older patients with $\mathrm{AD}$, the use of physical performance-based assessments used in general geriatric practice, such as handgrip strength and gait speed or the Short-Physical Performance Battery (SPPB) should be strongly considered [117-119], so that the data of frail patients can be analysed as a subgroup. Such efforts would greatly improve the reliability of recommendations for pharmacological therapy of physically frail patients.

\section{Conclusion}

Although today's frailty definition was introduced approximately 30 years ago and despite the recommendation by regulatory authorities that frail older patients be included in clinical trials, an exhaustive literature assessment identified only a few small studies that specifically included patients with physical frailty or significant functional impairment. Physically frail older patients appear to be severely underrepresented in clinical trials, although they represent the major users of many pharmaceuticals $[8-10] .$.

\section{Implications for practice}

The available data suggested small but significant improvements of cognition in AChEI-treated patients and good treatment tolerability. Antidepressants did not show any significant improvements in depressive symptoms or BPSD in general. Both antipsychotics and anticonvulsants demonstrated significant improvements in certain BPSD items, but also higher rates of adverse events. The overall data was of low to very low quality due to the small numbers of included patients, and therefore it is difficult to make treatment recommendations with any degree of confidence. This review highlights the overall lack of evidence regarding the efficiency of pharmacotherapy on AD and BPSD in frail older and significantly functional impaired patients. In the absence of better evidence, in general, an individual risk-benefit analysis should be performed, and pharmacological treatment should only be started if nonpharmacological interventions are insufficient. Frail older patients appear to possibly be more vulnerable to drug-induced AEs, and therefore, regular re-evaluation of drug therapy is beneficial [15].

\section{Implication for research}

Due to demographic changes, physical frailty will become more important in medical care, and it should be taken into greater account in study planning and reporting-for example, by implementing a standardized procedure in the CONSORT guidelines [41, 120]. One possible approach was demonstrated in a study that investigated the safety and efficacy of nilvadipine in patients with mild to moderate AD and included frail older patients in a planned substudy [121]. More clinical trials that include measures of physical function or frailty such as physical performance-based assessments and ADL scales are urgently needed. It would also be helpful if trials that include frail patients-even if this is only a subgroup-could separately identify these patients in the study results.

\section{Abbreviations \\ 95\% Cl: 95\% confidence interval; AChEl: Acetylcholinesterase inhibitor; ADL: Activities of daily living; AE: Adverse event; AIMS: Abnormal Involuntary Movement Scale; BPRS: Brief Psychiatric Rating Scale; BPSD: Behavioural and psychological symptoms of dementia; CERAD BRSD: Behavior Rating Scale for Dementia of the Consortium to Establish a Registry for Alzheimer's Disease; CDR-SoB: Clinical Dementia Rating - Sum of Boxes Score; CENT RAL: Cochrane Central Register of Controlled Trials; CGI-I: Clinical Global Impression (of Improvement); CMAl: Cohen-Mansfield Agitation Inventory; DIEPSS: Drug-Induced Extra-Pyramidal Symptom Scale; DMAS: Dementia Mood Assessment Scale; DSM: Diagnostic and Statistical Manual of Mental Disorders; EMA: European Medicines Agency; EPOC: The Effective Practice and Organisation of Care Group; FIM: Functional Independence Measure; GRADE: Grading of Recommendations, Assessment, Development and Evaluation; Ham-A: Hamilton Rating Scale for Anxiety; Ham-D: Hamilton Rating Scale for Depression; IADL: Instrumental activities of daily living; ICD: International Classification of Diseases; IQWiG: German Institute for Quality and Efficiency in Health Care; MCl: Mild cognitive impairment; MD: Mean difference; MDS: Minimum Data Set; MDS-ADL: Minimum Data Set - Activities of Daily Living; MedQoL: Medication and Quality of Life in frail older persons Research Group; MID: Minimally important difference; MMSE: Mini-Mental State Examination; MOSES: Multidimensional Observation Scale for Elderly Subjects; NINCDS-ADRDA: National Institute of Neurological and Communicative Disorders and Stroke and the Alzheimer's Disease and Related Disorders Association; NPI-NH: Neuropsychiatric Inventory - Nursing Home Version; OAS: Overt Aggression Scale; PRISMA: Preferred Reporting Items for Systematic Reviews and Meta-Analyses; PSMS: Physical Self- Maintenance Scale; RCT: Randomized controlled trial; RevMan: Review Manager; RR: Risk ratio; SAS: Simpson-Angus Scale; SD: Standard deviation; SIB: Severe Impairment Battery; SMD: Standardized mean difference; SoF: Summary of findings}

\section{Supplementary Information}

The online version contains supplementary material available at https://doi. org/10.1186/s13195-021-00867-8.

\section{Additional file 1.}

Additional file 2 .

Additional file 3.

Additional file 4.

Additional file 5 . 


\section{Additional file 6 .}

Additional file 7.

\section{Acknowledgements}

The authors are grateful to their fellow members of the MedQol Group for fruitful discussions and excellent cooperation with regard to further questions of diabetes, dementia and depression. The membership is as follows: University of Heidelberg: Walter E. Haefeli, Hanna M. Seidling (Department of Clinical Pharmacology and Pharmacoepidemiology), Jürgen M. Bauer, Annette Eidam (Agaplesion Bethanien Hospital Heidelberg); University of Freiburg: Claudia Bollig, Gabriel Torbahn, Sebastian Voigt-Radloff (Institute for Evidence in Medicine [for the Cochrane Germany Foundation], Faculty of Medicine, University Hospital Freiburg); University of Ulm: Simone Brefka, Dhayana Dallmeier, Michael D. Denkinger, Viktoria Mühlbauer (Agaplesion Bethesda Hospital, Department of Geriatrics, University of UIm and Geriatric Center Ulm/Alb-Donau), Carlos Schönfeldt-Lecuona (Department of Psychiatry and Psychotherapy III, University Hospital UIm and Geriatric Center Ulm/Alb-Donau), Christine von Arnim (University Medical Centre, Göttingen and Geriatric Center Ulm/Alb-Donau); University of Bern: Stefan Klöppel (University Psychiatric Service Bern [UPD], Department of Geriatric Psychiatry and Psychotherapy, University of Bern).

\section{Authors' contributions}

MS, MD, CSL, SV-R and CVA designed the research and study concept. MS and VM performed the dual review process, including screening of studies, risk of bias assessment, data extraction and analysis. MS wrote the first draft of the manuscript. JH, VM and CVA provided clinical expertise and critically revised the first draft of the manuscript. SK, SB, DD, MD, SV-R and CSL critically revised the manuscript. All authors granted final approval of the final manuscript to be published.

\section{Funding}

This work was financed by the open funding line of the special line "Medicine," an element of the University Funding Contract (Hochschulfinanzierungsvertrag) Baden-Württemberg, as part of the joint project "Medication and Life Circumstances in Old Age" ("Medikation und Lebenssituation im Alter"). Open Access funding enabled and organized by Projekt DEAL. We acknowledge support by the Open Access Publication Funds of the Göttingen University.

\section{Availability of data and materials}

The datasets used and analysed during the current review are available from the corresponding author on reasonable request.

\section{Declarations}

\section{Ethics approval and consent to participate}

05.07.2017, Ethics committee of the University of Ulm, Germany. Anonymized data only was used. No further approval required.

\section{Consent for publication}

Not applicable.

\section{Competing interests}

CVA received honoraria from serving on the scientific advisory board of Biogen, Roche, and Dr. Willmar Schwabe GmbH \&Co. KG and has received funding for travel and speaker honoraria from Lilly GmbH, Daiichi Sankyo, Biogen, Roche diagnostics AG and Dr. Willmar Schwabe GmbH \&Co. KG and has received research support from Roche diagnostics AG. The other authors declare that they have no competing interests.

\section{Author details}

${ }^{1}$ Department of Neurology, University Clinic UIm, Ulm, Germany. ${ }^{2}$ Agaplesion Bethesda Clinic, Institute for Geriatric Research, Ulm University, Ulm, Germany. ${ }^{3}$ Geriatric Center Ulm/Alb-Donau, Ulm, Germany. ${ }^{4}$ Center for Geriatric Medicine and Gerontology, Medical Center and Faculty of Medicine, University of Freiburg, Freiburg im Breisgau, Germany. ${ }^{5}$ nstitute for Evidence in Medicine (for Cochrane Germany Foundation), Medical Center and Faculty of Medicine, University of Freiburg, Freiburg im Breisgau, Germany. ${ }^{6}$ Department of Epidemiology, Boston University School of Public Health,
Boston, USA. 'Department of Psychiatry and Psychotherapy III, University Clinic Ulm, Ulm, Germany. ${ }^{8}$ University Hospital of Old Age Psychiatry, University of Bern, Bern, Switzerland. ${ }^{9}$ Division of Geriatrics, University Medical Centre, Georg August University, Robert-Koch-Str. 40, 37075 Göttingen, Germany.

Received: 29 April 2021 Accepted: 23 June 2021

Published online: 16 July 2021

\section{References}

1. Clegg A, Young J, lliffe S, Olde Rikkert M, Rockwood K. Frailty in older people. Lancet. 2013;381(9868):752-62. https://doi.org/10.1016/S0140-673 6(12)62167-9.

2. Word Health Organization. World report on ageing and health. 2015; Available at: http://apps.who.int/iris/bitstream/10665/186463/1/9789240694 811_eng.pdf. Accessed 18.12.2017.

3. Collard RM, Boter H, Schoevers RA, Oude Voshaar RC. Prevalence of frailty in community-dwelling older persons: a systematic review. J Am Geriatr Soc. 2012;60(8):1487-92. https://doi.org/10.1111/j.1532-5415.2012.04054.x.

4. Mayeux R, Stern Y. Epidemiology of Alzheimer disease. Cold Spring Harb Perspect Med. 2012;2(8). https://doi.org/10.1101/cshperspect.a006239.

5. Landi F, Liperoti R, Russo A, Capoluongo E, Barillaro C, Pahor M, et al. Disability, more than multimorbidity, was predictive of mortality among older persons aged 80 years and older. J Clin Epidemiol. 2010;63(7):752-9. https://doi.org/10.1016/j.jclinepi.2009.09.007.

6. Hall DE, Arya S, Schmid KK, Carlson MA, Lavedan P, Bailey TL, et al. Association of a Frailty Screening Initiative With Postoperative Survival at 30, 180, and 365 Days. JAMA Surg. 2017;152(3):233-40.

7. Kojima G, lliffe S, Walters K. Frailty index as a predictor of mortality: a systematic review and meta-analysis. Age Ageing. 2018;47(2):193-200.

8. Konrat C, Boutron I, Trinquart L, Auleley GR, Ricordeau P, Ravaud P. Underrepresentation of elderly people in randomised controlled trials. The example of trials of 4 widely prescribed drugs. Plos One. 2012;7(3):e33559.

9. Leinonen A, Koponen M, Hartikainen S. Systematic Review: Representativeness of Participants in RCTs of Acetylcholinesterase Inhibitors. Plos One. 2015;10(5):e0124500. https://doi.org/10.1371/journal. pone.0124500.

10. Schoenmaker N, Van Gool W,A. The age gap between patients in clinical studies and in the general population: a pitfall for dementia research. Lancet Neurol. 2004;3(10):627-630.

11. International Conference on Harmonisation of Technical Requirements for Registration of Pharmaceuticals for Human Use. ICH Harmonised Tripartite Guideline. Studies in Support of Special Populations: Geriatrics E7. 24.06. 1993; Available at: http://www.ich.org/fileadmin/Public_Web_Site/ICH_ Products/Guidelines/Efficacy/E7/Step4/E7_Guideline.pdf. Accessed 26.12. 2017.

12. European Medicines Agency, Committee for Medicinal Products for Human Use. Reflection paper on physical frailty: instruments for baseline characterisation of older populations in clinical trials.2018; Available at: https://www.ema.europa.eu/documents/scientific-guideline/reflection-paperphysical-frailty-instruments-baseline-characterisation-older-populationsclinical_en.pdf. Accessed 08.09.2018.

13. Singh S, Bajorek B. Defining 'elderly' in clinical practice guidelines for pharmacotherapy. Pharm Pract. 2014;12(4):489.

14. Kroger E, Mouls M, Wilchesky M, Berkers M, Carmichael P-, van Marum R, et al. Adverse drug reactions reported with cholinesterase inhibitors: an analysis of 16 years of individual case safety reports from VigiBase. Ann Pharmacother 2015;49(11):1197-1206, doi: https://doi.org/10.1177/106002801 5602274.

15. Turnheim K. When drug therapy gets old: pharmacokinetics and pharmacodynamics in the elderly. Exp Gerontol. 2003;38(8):843-53. https:// doi.org/10.1016/S0531-5565(03)00133-5.

16. Fried LP, Tangen CM, Walston J, Newman AB, Hirsch C, Gottdiener J, et al. Frailty in older adults: evidence for a phenotype. J Gerontol A Biol Sci Med Sci. 2001;56(3):M146-56. https://doi.org/10.1093/gerona/56.3.M146.

17. Walston J, Hadley E, Ferrucci L, Guralnik J, Newman A, Studenski S, et al. Research agenda for frailty in older adults: toward a better understanding of physiology and etiology: summary from the American Geriatrics Society/ National Institute on aging research conference on frailty in older adults. J Am Geriatr Soc 2006 06/01; 2020/06;54(6):991-1001. 
18. Rockwood K, Hogan D, MacKnight C. Conceptualisation and measurement of frailty in elderly people. Drugs Aging. 2000;17(4):295-302.

19. Hogan DB, MacKnight C, Bergman H. Canadian Initiative on Frailty and Aging. Models, definitions, and criteria of frailty. Aging Clin Exp Res. 2003; 15(3 Suppl):1-29.

20. Rockwood K, Mitnitski A. Frailty in relation to the accumulation of deficits. J Gerontol A Biol Sci Med Sci. 2007;62(7):722-7. https://doi.org/10.1093/ gerona/62.7.722

21. Buchman AS, Schneider JA, Leurgans S, Bennett DA. Physical frailty in olde persons is associated with Alzheimer disease pathology. Neurology. 2008; 71(7):499-504. https://doi.org/10.1212/01.wnl.0000324864.81179.6a.

22. Kulmala J, Nykanen I, Manty M, Hartikainen S. Association between frailty and dementia: a population-based study. Gerontology. 2014;60(1):16-21. https://doi.org/10.1159/000353859.

23. Clodomiro A, Gareri P, Puccio G, Frangipane F, Lacava R, Castagna A, et al. Somatic comorbidities and Alzheimer's disease treatment. Neurol Sci. 2013 34(9):1581-9. https://doi.org/10.1007/s10072-013-1290-3.

24. Buchman AS, Boyle PA, Wilson RS, Tang Y, Bennett DA. Frailty is associated with incident Alzheimer's disease and cognitive decline in the elderly. Psychosom Med. 2007;69(5):483-9. https://doi.org/10.1097/psy.0b013e31 8068de1d.

25. Mitnitski A, Fallah N, Rockwood MRH, Rockwood K. Transitions in cognitive status in relation to frailty in older adults: a comparison of three frailty measures. J Nutr Health Aging. 2011;15(10):863-7. https://doi.org/10.1007/ s12603-011-0066-9.

26. Soysal P, Isik AT, Stubbs B, Solmi M, Volpe M, Luchini C, et al. Acetylcholinesterase inhibitors are associated with weight loss in older people with dementia: a systematic review and meta-analysis. J Neurol Neurosurg Psychiatry. 2016;87(12):1368-74. https://doi.org/10.1136/jnnp-201 6-313660.

27. Cerejeira J, Lagarto L, Mukaetova-Ladinska EB. Behavioral and psychological symptoms of dementia. Front Neurol. 2012;3:73.

28. Sugimoto T, Ono R, Kimura A, Saji N, Niida S, Toba K, et al. Physical Frailty Correlates With Behavioral and Psychological Symptoms of Dementia and Caregiver Burden in Alzheimer's Disease. J Clin Psychiatry. 2018;79:e1-7. https://doi.org/10.4088/JCP.17m11991.

29. Boyé NDA, Van Lieshout EMM, Van Beeck EF, Hartholt KA, Van der Cammen TJM, Patka P. The impact of falls in the elderly. Trauma 2013 01/01; 2019/10; 15(1):29-35.

30. National Institute for Health and Care Excellence. NICE guideline Dementia: assessment, management and support for people living with dementia and their carers. 2018; Available at: https://www.nice.org.uk/guidance/ng97. Accessed 20.05.2021.

31. Cerreta F, Eichler H-, Rasi G. Drug Policy for an Aging Population - The European Medicines Agency's Geriatric Medicines Strategy. N Engl J Med 2012 11/22; 2017/12;367(21):1972-1974.

32. Shin IS, Carter M, Masterman D, Fairbanks L, Cummings JL. Neuropsychiatric symptoms and quality of life in Alzheimer disease. Am J Geriatr Psychiatry. 2005;13(6):469-74. https://doi.org/10.1097/00019442-200506000-00005.

33. Fick DM, Cooper JW, Wade WE, Waller JL, Maclean JR, Beers MH. Updating the Beers criteria for potentially inappropriate medication use in older adults: results of a us consensus panel of experts. Intemed. 2003;163(22): 2716-24.

34. Holt S, Schmiedl S, Thürmann P. Potentially inappropriate medications in the elderly: the PRISCUS list. Deutsches Ärzteblatt Int. 2010;107(31-32):54351.

35. Moher D, Liberati A, Tetzlaff J, Altman D, The PRISMA Group. Preferred Reporting Items for Systematic Reviews and Meta-Analyses: The PRISMA Statement. Plos Med 2009;6(7)(5/9/2017).

36. Higgins J, Green S, The Cochrane Collaboration. Cochrane Handbook for Systematic Reviews of Interventions Version 5.1.0. 2011; Available at: www. handbook.cochrane.org. Accessed 09.05.2017.

37. American Psychiatric Association. Diagnostic and Statistical Manual of Mental Disorders. 5th ed. Arlington: American Psychiatric Association; 2013.

38. American Psychiatric Association. Diagnostic and Statistical Manual of Mental Disorders. 4th ed. Washington: American Psychiatric Association; 2000

39. World Health Organization. The ICD-10 classification of mental and behavioural disorders: Clinical descriptions and diagnostic guidelines. 1992.

40. McKhann G, Drachman D, Folstein M, Katzman R, Price D, Stadlan E. Clinical diagnosis of Alzheimer's disease: report of the NINCDS-ADRDA Work Group under the auspices of Department of Health and Human Services Task Force on Alzheimer's Disease. Neurology. 1984;34(7):939-44.

41. Brefka S, Dallmeier D, Muehlbauer V, von Arnim CAF, Bollig C, Onder G, et al. A proposal for the retrospective identification and categorization of older people with functional impairments in scientific studies recommendations of the Medication and Quality of Life in Frail Older Persons (MedQoL) Research Group. J Am Med Direct Assoc. 2019;20(2):13846.

42. Seibert M. Anwendbarkeit von medikamentöser Therapie der Alzheimer Demenz sowie behavioraler und psychologischer Symptome der Demenz (BPSD) bei funktionell beeinträchtigten Patienten („frail elderly"): Eine systematische Übersichtsarbeit (Protokoll). 2017.

43. Institut für Qualität und Wirtschaftlichkeit im Gesundheitswesen (IQWiG). Abschlussbericht A05-19A: Cholinesterasehemmer bei Alzheimer Demenz. 2007; Available at: https://www.iqwig.de/download/A05-19A_A bschlussbericht_Cholinesterasehemmer_bei_Alzheimer_Demenz.pdf. Accessed 26.07.2018.

44. Committee for Medicinal Products for Human Use. Guideline on the clinical investigation of medicines for the treatment of Alzheimer's disease. 2018; Available at: https://www.ema.europa.eu/en/documents/scientific-guideline/ guideline-clinical-investigation-medicines-treatment-alzheimers-diseaserevision-2_en.pdf. Accessed 21.08.2019.

45. Buchner DM, Wagner EH. Preventing Frail Health. Clin Geriatr Med. 1992; $8(1): 1-18$

46. Covidence, Cochrane Collaboration, Instituto de Efectividad Clinica Y Sanitaria (EROS), Alfred Hospital Melbourne. Covidence. 2017; Available at: https://www.covidence.org/. Accessed 29.08.2017.

47. Cochrane Effective Practice and Organisation of Care (EPOC). Data collection form. EPOC Resources for review authors, 2017. 2017; Available at: http:// epoc.cochrane.org/epoc-specific-resources-review-authors. Accessed 19.05 2018.

48. Higgins JP, Altman DG, Gotzsche PC, Juni P, Moher D, Oxman AD, et al. The Cochrane Collaboration's tool for assessing risk of bias in randomised trials. BMJ. 2011:343(oct18 2):d5928. https://doi.org/10.1136/bmj.d5928.

49. The Nordic Cochrane Centre. Review Manager (RevMan) 5.3. 2014.

50. Guyatt GH, Oxman AD, Vist GE, Kunz R, Falck-Ytter Y, Alonso-Coello P, et al. GRADE: an emerging consensus on rating quality of evidence and strength of recommendations. BMJ. 2008;336(7650):924-6. https://doi.org/10.1136/ bmj.39489.470347.AD

51. Atkins D, Best D, Briss PA, Eccles M, Falck-Ytter $Y$, Flottorp S, et al. Grading quality of evidence and strength of recommendations. BMJ. 2004;328(7454): 1490. https://doi.org/10.1136/bmj.328.7454.1490.

52. Schünemann H, Brożek J, Guyatt G, Oxman A. Handbook for grading the quality of evidence and the strength of recommendations using the GRADE approach. 2013; Available at: gdt.guidelinedevelopment.org/app/handbook/ handbook.html. Accessed 20.07.19.

53. Cohen J. 2.2.3 "Small," "Medium," and "Large" d Values. In: Lawrence Erlbaum Associates $H$, editor. Statistical Power Analysis for the Behavioral Sciences. 2nd ed.; 1988. p. 24-26.

54. Guyatt GH, Oxman AD, Kunz R, Brozek J, Alonso-Coello P, Rind D, et al. GRADE guidelines 6. Rating the quality of evidence - imprecision. J Clin Epidemiol. 2011 ;:64(12):1283-93. https://doi.org/10.1016/j.jclinepi.2011.01.012.

55. Evidence Prime I, McMaster University. GRADEpro GDT: GRADEpro Guideline Development Tool. 2015

56. Petracca GM, Chemerinski E, Starkstein SE. A double-blind, placebocontrolled study of fluoxetine in depressed patients with Alzheimer's disease. Int Psychogeriatr. 2001;13(2):233-40. https://doi.org/10.1017/S1041 61020100761X.

57. Burns A, Bernabei R, Bullock R, Cruz Jentoft AJ, Frölich L, Hock C, et al. Safety and efficacy of galantamine (Reminyl) in severe Alzheimer's disease (the SERAD study): a randomised, placebo-controlled, doubleblind trial. Lancet Neurol. 2009;8(1):39-47. https://doi.org/10.1016/S14 74-4422(08)70261-8

58. Tariot PN, Cummings JL, Katz IR, Mintzer J, Perdomo CA, Schwam EM, et al. A randomized, double-blind, placebo-controlled study of the efficacy and safety of donepezil in patients with Alzheimer's disease in the nursing home setting. J Am Geriatr Soc. 2001;49(12):1590-9. https://doi.org/10.1111/ j.1532-5415.2001.49266.x

59. Petracca G, Teson A, Chemerinski E, Leiguarda R, Starkstein SE. A doubleblind placebo-controlled study of clomipramine in depressed patients with Alzheimer's disease. J Neuropsychiatry Clin Neurosci. 1996;8(3):270-5. 
60. Olin JT, Fox LS, Pawluczyk S, Taggart NA, Schneider LS. A pilot randomized trial of carbamazepine for behavioral symptoms in treatment-resistant outpatients with Alzheimer disease. Am J Geriatr Psychiatry. 2001;9(4):400-5. https://doi.org/10.1097/00019442-200111000-00008.

61. Porsteinsson AP, Tariot PN, Erb R, Cox C, Smith E, Jakimovich L, et al. Placebo-controlled study of divalproex sodium for agitation in dementia. Am J Geriatr Psychiatry. 2001;9(1):58-66. https://doi.org/10.1097/00019442-2 00102000-00009.

62. Tariot PN, Erb R, Leibovici A, Podgorski CA, Cox C, Asnis J, et al. Carbamazepine treatment of agitation in nursing home patients with dementia: a preliminary study. J Am Geriatr Soc. 1994;42(11):1160-6. https:// doi.org/10.1111/j.1532-5415.1994.tb06982.x.

63. Tariot PN, Erb R, Podgorski CA, Cox C, Patel S, Jakimovich L, et al. Efficacy and tolerability of carbamazepine for agitation and aggression in dementia. Am J Psychiatry. 1998;155(1):54-61. https://doi.org/10.11 76/ajp.155.1.54.

64. Tariot PN, Schneider L, Katz IR, Mintzer JE, Street J, Copenhaver M, et al. Quetiapine treatment of psychosis associated with dementia: a doubleblind, randomized, placebo-controlled clinical trial. Am J Geriatr Psychiatry. 2006;14(9):767-76. https://doi.org/10.1097/01.JGP.0000196628.12010.35.

65. Teranishi M, Kurita M, Nishino S, Takeyoshi K, Numata Y, Sato T, et al. Efficacy and tolerability of risperidone, yokukansan, and fluvoxamine for the treatment of behavioral and psychological symptoms of dementia: a blinded, randomized trial. J Clin Psychopharmacol. 2013;33(5):600-7. https:// doi.org/10.1097/JCP.0b013e31829798d5.

66. de Caires S, Steenkamp V. Use of Yokukansan (TJ-54) in the treatment of neurological disorders: a review. Phytother Res. 2010;24(9):1265-70. https:// doi.org/10.1002/ptr.3146.

67. Kawakami Z, Kanno H, Ueki T, Terawaki K, Tabuchi M, Ikarashi Y, et al. Neuroprotective effects of yokukansan, a traditional Japanese medicine, on glutamate-mediated excitotoxicity in cultured cells. Neuroscience. 2009; 159(4):1397-407. https://doi.org/10.1016/j.neuroscience.2009.02.004.

68. Swinne C, Cornette P, Schoevaerdts D, Latteur V, Melon C. Frailty in the medical literature. Ageing. 1998;27(3):411-3.

69. Bayer A, Tadd W. Unjustified exclusion of elderly people from studies submitted to research ethics committee for approval: descriptive study. BMJ. 2000;321(7267):992-3.

70. Hempenius L, Slaets JPJ, Boelens MAM, van Asselt DZB, de Bock GH, Wiggers $T$, et al. Inclusion of frail elderly patients in clinical trials: Solutions to the problems. J Geriatr Oncol. 2013 01/01; 2019/07;4(1):26-31.

71. Rehman HU. Under-representation of the elderly in clinical trials. Eur J Intern Med. 2005;16(6):385-6.

72. Birks JS. Cholinesterase inhibitors for Alzheimer's disease. Cochrane Database Syst Rev. 2006;1. https://doi.org/10.1002/14651858.CD005593.

73. Institute for Quality and Efficiency in Health Care (IQWiG). Abschlussbericht A05-19A: Cholinesterasehemmer bei Alzheimer Demenz. 2007; Available at: https://www.iqwig.de/download/A05-19A_Abschlussbericht_Cholinestera sehemmer_bei_Alzheimer_Demenz.pdf. Accessed 18.07.2018.

74. Birks J, Harvey RJ. Donepezil for dementia due to Alzheimer's disease. Cochrane Database Syst Rev. 2006;1

75. Black SE, Doody R, Li H, McRae T, Jambor KM, Xu Y, et al. Donepezi preserves cognition and global function in patients with severe Alzheimer disease. Neurology. 2007;69(5):459.

76. Winblad B, Kilander L, Eriksson S, Minthon L, Båtsman S, Wetterholm AL, et al. Donepezil in patients with severe Alzheimer's disease: double-blind, parallel-group, placebo-controlled study. Lancet (london). 2006;367(9516): 1057-65.

77. Blanco-Silvente L, Castells X, Saez M, Barcelo MA, Garre-Olmo J, VilaltaFranch J, et al. Discontinuation, efficacy, and safety of cholinesterase inhibitors for Alzheimer's disease: a meta-analysis and meta-regression of 43 randomized clinical trials enrolling 16106 patients. ijnp 2017 02/13; 9/26; 20(7):519-528.

78. Isik AT, Soysal P, Stubbs B, Solmi M, Basso C, Maggi S, et al. Cardiovascular outcomes of cholinesterase inhibitors in individuals with dementia: a metaanalysis and systematic review. J Am Geriatr Soc. 2018;66(9):1805-11.

79. Monacelli F, Rosa GM. Cholinesterase inhibitors: cardioprotection in Alzheimer's disease. J Alzheimer's Dis, 42 2014;4:1071-1077.

80. Azermai M, Petrovic M, Elseviers MM, Bourgeois J, Van Bortel LM, Vander Stichele $\mathrm{RH}$. Systematic appraisal of dementia guidelines for the management of behavioural and psychological symptoms. Ageing Res Rev. 2012;11(1):78-86
81. Dudas R, Malouf R, McCleery J, Dening T. Antidepressants for treating depression in dementia. Cochrane Database Syst Rev. 2018;8.

82. Henry G, Williamson D, Tampi RR. Efficacy and tolerability of antidepressants in the treatment of behavioral and psychological symptoms of dementia, a literature review of evidence. Am J Alzheimers Dis Other Demen 2011 05/ 01; 2019/09;26(3):169-183.

83. Thompson S, Herrmann N, Rapoport MJ, Lanctôt K,L. Efficacy and safety of antidepressants for treatment of depression in Alzheimer's disease: a metaanalysis. Can J Psychiatry 2007 04/01; 2019/09;52(4):248-255.

84. Mossello E, Boncinelli M, Caleri V, Cavallini MC, Palermo E, Di Bari M, et al. Is antidepressant treatment associated with reduced cognitive decline in Alzheimer's disease? Dement Geriatr Cogn Disord. 2008;25(4):372-9. https:// doi.org/10.1159/000121334.

85. Aboukhatwa M, Dosanjh L, Luo Y. Antidepressants are a rational complementary therapy for the treatment of Alzheimer's disease. Mol Neurodegen. 2010;5:10.02.2020-17.

86. Baillon SF, Narayana U, Luxenberg JS, Clifton AV. Valproate preparations for agitation in dementia. Cochrane Database Syst Rev. 2018;10.

87. Ballard CG, Gauthier S, Cummings JL, Brodaty H, Grossberg GT, Robert P, et al. Management of agitation and aggression associated with Alzheimer disease. Nat Rev Neurol. 2009:5(5):245-55.

88. Yeh Y, Ouyang W. Mood stabilizers for the treatment of behavioral and psychological symptoms of dementia: an update review. Kaohsiung J Med Sci. 2012;28(4):185-93.

89. Eddy CM, Rickards HE, Cavanna AE. The cognitive impact of antiepileptic drugs. Ther Adv Neurol Disord. 2011;4(6):385-407.

90. Moore AR, O'Keeffe ST. Drug-induced cognitive impairment in the elderly. Drugs Aging. 1999;15(1):15-28.

91. Fleisher AS, Truran D, Mai JT, Langbaum JBS, Aisen PS, Cummings JL, et al. Chronic divalproex sodium use and brain atrophy in Alzheimer disease. Neurology. 2011;77(13):1263.

92. Lonergan E, Luxenberg J. Valproate preparations for agitation in dementia. Cochrane Database Syst Rev. 2009;3.

93. Haasum Y, Johnell K. Use of antiepileptic drugs and risk of falls in old age: a systematic review. Epilepsy Res. 2017;138:98-104.

94. Maximos M, Chang F, Patel T. Risk of falls associated with antiepileptic drug use in ambulatory elderly populations: a systematic review. Can Pharm J. 2017:150(2):101-11.

95. The National Institute for Health and Care Excellence (NICE). Management of aggression, agitation and behavioural disturbances in dementia: carbamazepine. 2015; Available at: https://www.nice.org.uk/advice/esuom4 0/chapter/Full-evidence-summary. Accessed 11.10.2019.

96. Hollis J, Grayson D, Forrester L, Brodaty H, Touyz S, Cumming R. Antipsychotic Medication Dispensing and Risk of Death in Veterans and War Widows 65 Years and Older. Am J Geriatr Psychiatry. 2007;15(11):932-41.

97. Konovalov S, Muralee S, Tampi RR. Anticonvulsants for the treatment of behavioral and psychological symptoms of dementia: a literature review. Int Psychogeriatr. 2008;20(2):293-308. https://doi.org/10.1017/S10416102 07006540 .

98. Ballard CG, Waite J, Birks J. Atypical antipsychotics for aggression and psychosis in Alzheimer's disease. Cochrane Database Syst Rev. 2006;1.

99. Lonergan E, Luxenberg J, Colford JM, Birks J. Haloperidol for agitation in dementia. Cochrane Database Syst Rev. 2002;2. https://doi.org/10.1002/14 651858.CD003945

100. Ballard C, Margallo-Lana M, Juszczak E, Douglas S, Swann A, Thomas A, et al. Quetiapine and rivastigmine and cognitive decline in Alzheimer's disease: randomised double blind placebo controlled trial. BMJ. 2005;330(7496):874.

101. McShane R, Keene J, Gedling K, Fairburn C, Jacoby R, Hope T. Do neuroleptic drugs hasten cognitive decline in dementia? Prospective study with necropsy follow up. BMJ. 1997;314(7076):266.

102. Schneider LS, Dagerman K, Insel PS. Efficacy and adverse effects of atypical antipsychotics for dementia: meta-analysis of randomized, placebocontrolled trials. Am J Geriatr Psychiatry. 2006;14(3):191-210.

103. Livingston G, Walker AE, Katona CLE, Cooper C. Antipsychotics and cognitive decline in Alzheimer's disease: the LASER-Alzheimer's disease longitudinal study. J Neurol Neurosurg Psychiatr. 2007:78(1):25-9.

104. Wilson RS, Gilley DW, Bennett DA, Beckett LA, Evans DA. Hallucinations, delusions, and cognitive decline in Alzheimer's disease. J Neurol Neurosurg Psychiatr. 2000;69(2):172.

105. Emanuel JE, Lopez OL, Houck PR, Becker JT, Weamer EA, Demichele-Sweet MAA, et al. Trajectory of cognitive decline as a predictor of psychosis in 
early Alzheimer disease in the cardiovascular health study. Am J Geriatr Psychiatry. 2011;19(2):160-8. https://doi.org/10.1097/JGP.0b013e3181e446c8.

106. Suh G, Son HG, Ju Y, Jcho KH, Yeon BK, Shin YM, et al. A randomized, double-blind, crossover comparison of risperidone and haloperidol in Korean dementia patients with behavioral disturbances. Am J Geriatr Psychiatry. 2004;12(5):509-16.

107. Chan WC, Lam LC, Choy CN, Leung VP, Li SW, Chiu HF. A double-blind randomised comparison of risperidone and haloperidol in the treatment of behavioural and psychological symptoms in Chinese dementia patients. Int J Geriatr Psychiatry. 2001;16(12):1156-62. https://doi.org/10.1 002/gps.504.

108. Langballe EM, Engdahl B, Nordeng H, Ballard C, Aarsland D, Selbæk G. Short- and long-term mortality risk associated with the use of antipsychotics among 26,940 dementia outpatients: a population-based study. Am J Geriatr Psychiatry. 2014;22(4):321-31.

109. Sacchetti E, Turrina C, Valsecchi P. Cerebrovascular accidents in elderly people treated with antipsychotic drugs. Drug Saf. 2010;33(4): 273-88.

110. Schneider LS, Dagerman KS, Insel P. Risk of death with atypical antipsychotic drug treatment for dementiameta-analysis of randomized placebo-controlled trials. JAMA. 2005;294(15):1934-43.

111. Gardette V, Lapeyre-Mestre M, Coley N, Cantet C, Montastruc JL, Vellas B, et al. Antipsychotic use and mortality risk in community-dwelling Alzheimer's disease patients: evidence for a role of dementia severity. Curr Alzheimer Res. 2012;9(9):1106-16. https://doi.org/10.2174/156720512803 569037

112. Lopez OL, Becker JT, Chang YF, Sweet RA, Aizenstein H, Snitz B, et al. The long-term effects of conventional and atypical antipsychotics in patients with probable Alzheimer's disease. Am J Psychiatry. 2013;170(9):1051-8. https://doi.org/10.1176/appi.ajp.2013.12081046.

113. The 2019 American Geriatrics Society Beers Criteria (R) Update Expert Panel. American Geriatrics Society 2019 Updated AGS Beers Criteria(R) for Potentially Inappropriate Medication Use in Older Adults. J Am Geriatr Soc. 2019. 67(4):674-694.

114. Deuschl G, Maier W. S3-Leitlinie Demenzen. Deutsche Gesellschaft für Neurologie, Leitlinien für Diagnostik und Therapie in der Neurologie. 2016.

115. Van Leeuwen E, Petrovic M, van Driel ML, De Sutter Al, Vander Stichele $\mathrm{R}$, Declercq $\mathrm{T}$, et al. Withdrawal versus continuation of long-term antipsychotic drug use for behavioural and psychological symptoms in older people with dementia. Cochrane Database Syst Rev. 2018;3: CD007726.

116. Ballard C, Hanney ML, Theodoulou M, Douglas S, McShane R, Kossakowski K, et al. The dementia antipsychotic withdrawal trial (DART-AD): long-term follow-up of a randomised placebo-controlled trial. Lancet Neurol. 2009;8(2): 151-7. https://doi.org/10.1016/S1474-4422(08)70295-3.

117. Bohannon RW. Muscle strength: clinical and prognostic value of hand-grip dynamometry. Curr Opin Clin Nutr Metab Care. 2015;18(5):465-70. https:// doi.org/10.1097/MCO.0000000000000202.

118. Guralnik JM, Simonsick EM, Ferrucci L, Glynn RJ, Berkman LF, Blazer DG, et al. A short physical performance battery assessing lower extremity function: association with self-reported disability and prediction of mortality and nursing home admission. J Gerontol. 1994;49(2):M85-94. https://doi. org/10.1093/geronj/49.2.M85.

119. Binotto MA, Lenardt MH, Rodríguez-Martínez MDC. Physical frailty and gait speed in community elderly: a systematic review. Rev Esc Enferm USP 2018; 52:e03392-220X2017028703392.

120. Schulz KF, Altman DG, Moher D. CONSORT 2010 Statement: updated guidelines for reporting parallel group randomised trials. BMJ. 2010;340: c332.

121. Meulenbroek O, O'Dwyer S, de Jong D, van Spijker G, Kennelly S, Cregg $F$, et al. European multicentre double-blind placebo-controlled trial of Nilvadipine in mild-to-moderate Alzheimer's disease-the substudy protocols: NILVAD frailty; NILVAD blood and genetic biomarkers; NILVAD cerebrospinal fluid biomarkers; NILVAD cerebral blood flow. BMJ Open. 2016;6(7):e011584

\section{Publisher's Note}

Springer Nature remains neutral with regard to jurisdictional claims in published maps and institutional affiliations.

Ready to submit your research? Choose BMC and benefit from:

- fast, convenient online submission

- thorough peer review by experienced researchers in your field

- rapid publication on acceptance

- support for research data, including large and complex data types

- gold Open Access which fosters wider collaboration and increased citations

- maximum visibility for your research: over $100 \mathrm{M}$ website views per year

At BMC, research is always in progress.

Learn more biomedcentral.com/submissions 